\title{
Disruptive technologies in agricultural operations: a systematic review of Al-driven AgriTech research
}

\author{
Konstantina Spanaki ${ }^{1}$. Uthayasankar Sivarajah ${ }^{2}$ (D) Masoud Fakhimi ${ }^{3}$. \\ Stella Despoudi ${ }^{4,5}$ (D) Zahir Irani ${ }^{2}$ (D)
}

Accepted: 24 December 2020 / Published online: 18 January 2021

(c) The Author(s) 2021

\begin{abstract}
The evolving field of disruptive technologies has recently gained significant interest in various industries, including agriculture. The fourth industrial revolution has reshaped the context of agricultural technology (AgriTech) with applications of artificial intelligence (AI) and a strong focus on data-driven analytical techniques. Motivated by the advances in AgriTech for agrarian operations, the study presents a state-of-the-art review of the research advances which are, evolving in a fast pace over the last decades (due to the disruptive potential of the technological context). Following a systematic literature approach, we develop a categorisation of the various types of AgriTech, as well as the associated AIdriven techniques which form the continuously shifting definition of AgriTech. The contribution primarily draws on the conceptualisation and awareness about AI-driven AgriTech context relevant to the agricultural operations for smart, efficient, and sustainable farming. The study provides a single normative reference for the definition, context and future directions of the field for further research towards the operational context of AgriTech. Our findings indicate that AgriTech research and the disruptive potential of AI in the agricultural sector are still in infancy in Operations Research. Through the systematic review, we also intend to inform a wide range of agricultural stakeholders (farmers, agripreneurs, scholars and practitioners) and to provide research agenda for a growing field with multiple potentialities for the future of the agricultural operations.
\end{abstract}

Keywords Disruptive technologies $\cdot$ Agricultural operations $\cdot$ Agricultural technology (AgriTech) $\cdot$ Artificial intelligence $(\mathrm{AI}) \cdot$ Systematic literature review

Konstantina Spanaki

K.Spanaki@lboro.ac.uk

1 School of Business and Economics, Loughborough University, Loughborough Leicestershire LE11 3TU, UK

2 School of Management, University of Bradford, Emm Lane, Bradford BD9 4JL, UK

3 Surrey Business School, University of Surrey, Guildford GU2 7XH, UK

4 School of Economic Sciences, University of Western Macedonia, Grevena, Greece

5 Aston Business School, Aston University, Birmingham B4 7ET, UK 


\section{Introduction}

The last decade has gone through a data-driven evolution in multiple sectors and fields. The fourth industrial revolution (Industry 4.0) is vast and spans from the rise of social media to smart devices resulting in the development of ground-breaking innovative digital operating models, leading to radical changes to the lifestyle and the daily lives of individuals (George et al. 2014; Knippenberg et al. 2015; Mikalef and Pateli 2017). The data-driven evolution and emergent technologies can generate different kinds of value; value in terms of business and societal goals (Günther et al. 2017; Mikalef et al. 2020), but also can lead to the creation of sustainable societies (Pappas et al. 2018). In the agricultural field, unlike most of the technological disruptions, the transition from conventional operating models of farming to modern but also to smart data-driven ones come out of necessity to feed the ever-growing population coupled with environmental triggers (Yahya 2018). As highlighted in the United Nations Sustainable Development Goals (UN SDGs), food security is a key goal that should bring to the table serious intent and innovative solutions as it is highlighted through subsequent UN reports (2017a, 2017b, 2017c), and recent studies (Sharif and Irani 2017).

The current farming methods and models of conventional agricultural processes, where the focus was on mass production of food, led to an unsustainable solution both for the environment and for the individuals and societies on a long-term basis (Tripicchio et al. 2015). While farming more land will not be a viable solution anymore, alternative ways should be followed in order to increase the yield and crops (Wolfert et al. 2017). Therefore, the arising requirements for a redesign of the farming production call for innovative sustainability-oriented smart solutions applied in the farming fields (Fountas et al. 2015; Lampridi et al. 2019). Within this context, disruptive technologies have a critical role to play, through the development of breakthrough ideas for precise agricultural processes, data analytics and AI techniques (Miranda et al. 2019). Feeding the future population relies highly on a sustainable agricultural system; therefore an optimal solution for the sustainability could be viewed through the applications of smart and precision techniques in agrarian operations (for the problems associated with the arable land and environmental efficiency).

The flourishing field of Agricultural Technology (AgriTech) and the interest in relevant investments come as no surprise, as well as a growing enthusiasm from practitioners and researchers from various fields, with regards to the AI application of AgriTech in the associated operations and practices (Boshkoska et al. 2019; Carayannis et al. 2018; Lezoche et al. 2020). The field of Agriculture has immerse potential to benefit from the technological disruption (Kaloxylos et al. 2012; Nukala et al. 2016; Wolfert et al. 2017), through the use of technologies as the Internet of Things (IoT), sensors, smart devices, Big Data Analytics, as well as Machine Learning (ML) and a vast range of techniques of Artificial Intelligence (AI). Recent studies like those of Boshoska et al. (2019) present decision support systems for knowledge dissemination across agri-food value chains and also Lezoche et al (2020) with an initial scoping survey around the term of Agriculture 4.0, identify the lack of research from an operational perspective and open the way forward for more studies around data-driven technological advances in the fields of agricultural operations. There is still a wide scope in the operations field to explore the processes, practices and the overall disruption of the agricultural sector due to the AI applications of AgriTech. The review of the extant literature will define the term of AgriTech, explore the context, develop a research agenda, and act as a normative reference for future research. 
Initially, in this study, the focus is on exploring the AgriTech evolution throughout the last decade, in order to provide a definition of the term "AgriTech" associated with the recent advances of the field and linked to AI-driven applications. Secondly, through a synthesis of 205 studies, the review identifies the various types and techniques applied in the agricultural operations relevant to the context of "technology for the farming operations". Following this direction, through the pool of studies identified and analysed for the systematic review, the paper iteratively distinguishes the Artificial Intelligence (AI) techniques for the farm management cycle and subsequent implications for the Agricultural Operations. Finally, the study provides a review of the implications of AI-driven AgriTech in Agricultural Operations, potential applications for the Agricultural Sector and the multiple opportunities and challenges for research and practice.

\section{The evolution of agricultural technology (AgriTech)}

The introduction of technology in the agricultural processes originates back to the centuries since the Agricultural Age (ancient years-appx 9000 BC), and dates to the Information Age and the "Big Data" Evolution which recently expands to various sectors. The need for technology in the farming field stems from the strong motivation to feed the world population; which evolved the agricultural area through the years to facilitate modern practices and processes to meet the ever-growing needs (Corallo et al. 2018). Applications of technology in farming are attempting to enhance the agrarian operations through sophisticated information and communication developments (Tsolakis, Bechtsis, and Bochtis 2019; Tsolakis, Bechtsis, and Srai 2019). Aspects of the agricultural industry such as crop cultivation management and control, quality management, transport of food products and food preservation may all be enhanced by taking into account their domain-specific requirements and translating them into the respective functional design, development and applications by ICT experts (Barmpounakis et al. 2015; Miranda et al. 2019).

Agricultural Technology (AgriTech) is not defined always in the same way; the current definition is strongly associated with AI applications and refers to the progression from farming to smart farming, which flourished in three periods (Miranda et al. 2019; Wolfert et al. 2017). Initially, the Agricultural Evolution which has started from ancient years to approximately 1920s and infers mostly to the pre-industrial agriculture. Characteristics and advancements of this period include the labour intensity and essential subsistence farming in the form of small-scale farms (the agricultural activities as a focus on feeding the farmer's family). As technology evolved rapidly during the Industrial Evolution, the model of industrial and massive agriculture started to arise, following a high industrialised pattern. The robust industrialisation of agriculture was transformed with technological advances like tractors, harvesters, chemical fertilisers and seeds, and developed the model of the large-scale commercial farms. However, the industrial model of farming was proven unsustainable (Darnhofer et al. 2009; Miranda et al. 2019; Rigby et al. 2001; Wezel et al. 2009, 2014). Recently, new practices were introduced based on data-intensive disruptive ways for solving agricultural problems (Miranda et al. 2019; Wolfert et al. 2017) introducing an unpreceded AI-driven approach for Agricultural Technology (AgriTech). Table 1 illustrates the progression stages from conventional farming to modern and smart farming.

The Information and Data Evolution, as well as Artificial Intelligence (AI) techniques, have entered the smart and precision agriculture, which is characterised by the exploitation of disruptive technologies (e.g. multi-source data, sensors on farm equipment and plants, 


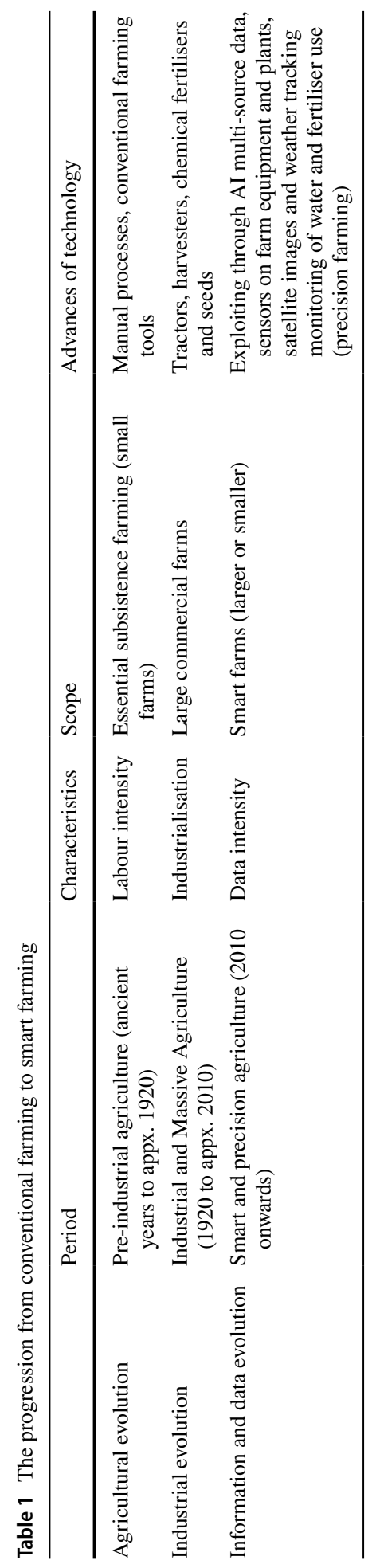


satellite images and weather tracking, monitoring of water and fertiliser use) for precision farming. The model of data-intensive agriculture is applied in both large-scale and smallscale farms and transforms the way they operate while providing multiple forms of value for the farmer, consumer, as well as the society (Miranda et al. 2019).

The rapid evolution of AgriTech motivates the study herein, as the technology was always a part of the agricultural practices, even in pre-industrial farming operations. However, the AI applications of disruptive technologies in the agrarian fields and the modern smart farming operating models, present an AI-driven approach of AgriTech that should be further discussed. The study initially has a view to developing a categorisation of the various types and techniques which define the term "AgriTech" within the studies of the last decade and explore a future research agenda for consideration. Numerous studies disparately describe AgriTech, mainly from a solution-driven perspective (more than 200 as identified from the systematic review). However, there are only a few of recent AgriTech studies to provide a clear link of AI-applications with a business and operations focus. So far, AgriTech research refers solely on the technical aspects and not the operational background surrounding the applications as a single source of normative text that culminates historical works and, outlines foresight research. Therefore, a systematic review and synthesis of the extant literature will act as a single reference source to motivate new insights of AI-driven AgriTech research and applications from an operations perspective.

\section{Research methodology}

The study follows a systematic review research design to synthesise and present a comprehensive, structured analysis of the normative literature in the scope of "Technology for Agricultural Operations". Thus, the research builds on the Systematic Literature Review (SLR) methodology proposed by Tranfield et al. (2003) to review the extant field. The evidence-based reviews as proposed by Tranfield et al. (2003) is a successfully employed methodology for a systematic and state-of-the-art comprehensive way to review the literature in the various fields of management ( see, e.g. Adams et al. 2015; Colicchia and Strozzi 2012; Delbufalo 2012; Kitchenham et al. 2009; Sivarajah et al. 2017; Spanaki et al. 2018). According to Tranfield et al. (2003), undertaking a literature review to provide the manifestation for enlightening policy and practice in any discipline, is a key research objective for the academic and practitioner communities. This further adds to the significance of such literature review papers that may further result in aiding evidence-based decision-making in future research endeavours. The study followed the methodology of evidence-based reviews (Denyer and Tranfield 2009; Tranfield et al. 2003) which differs from the conventional narrative reviews through a systematic, structured and explicit approach in the selection of the studies in Agricultural Technology and Operations area (at every stage in this paper), employing rigorous and reproducible methods of evaluation.

Seminal literature on SLR process (e.g. Delbufalo 2012; Kitchenham et al. 2009, 2012) assert that an SLR is designed to (a) support in generating a sense of joint effort, importance and openness between the research studies in order to impede unproductive recurrence of effort, (b) support in connecting potential research to the queries and issues that have been modelled by previous research studies (e.g. most of those paper reviewed as part of this research exercise) and (c) develop the approaches employed to assemble and synthesise preceding pragmatic evidence. In the interest of parsimony, a meticulous though 
not exhaustive SLR was carried out in this paper by following the three-stage approach (Tranfield et al. 2003):

- Stage 1-Planning the review process-defining the research aim and objectives; preparing the proposal and developing the review protocol;

- Stage 2-Conducting the Review Process-Identifying, selecting, evaluating, and synthesising the pertinent research studies; and

- Stage 3-Reporting and Dissemination of the Overall Research Results-Descriptive reporting of results and thematic reporting of journal articles.

Following the three-stage approach, the next Sect. 3.1 summarises the definition of the aim and objectives, including the proposal and Sect. 3.2. summarises the review protocol. Sect. 3.3 describes the Scopus database searching process of the relevant articles. An overview of the selected studies is presented in 3.4, where the study demographics are discussed in brief to provide an initial view of the field. Finally, the reporting and dissemination the overall results will be discussed in the following sections of the paper.

\subsection{Defining the research aim and objectives and preparing the proposal}

As highlighted in the introduction section, this research aims to present a comprehensive systematic review of the Agricultural Technology (AgriTech) applications and techniques theorised/proposed/employed AI for Agricultural Operations to provide a holistic understanding of this landscape with the objective of making sound investment decisions. In doing so, the paper's focus is on systematically analysing and synthesising the extant research published in Agricultural Operations area. More specifically, the authors seek to answer the following three principal questions:

- Question 1: What are the various disruptive technologies presented for the operations management processes of the Agricultural sector over the last decades?

- Question 2: What are the distinct types and categories of Agricultural Technology (AgriTech)?

- Question 3: What is the role of artificial intelligence (AI) for AgriTech applications in agricultural operations?

\subsection{The review protocol}

The review protocol was developed around three questions as mentioned in a previous section (i.e. Q1, Q2 and Q3) by following the prescriptive three-staged approach. Essentially, the responses to the question Q3 results from the review of the 205 papers for Q1 and Q2. The review process ensured that the seven conditions highlighted in Table 2 were strictly adhered to ensure that an effective and reproducible database examining process highlighting the inclusion and exclusion criteria for each of the review process.

\subsection{Scopus database searching process and results}

The use of databases step of the review protocol reports on the steps and activities of the database searching process and demonstrates the outcomes both descriptively and 
Table 2 The review protocol

\begin{tabular}{|c|c|}
\hline Review conditions & Description \\
\hline Use of database & $\begin{array}{l}\text { Scopus database was used to undertake the search for published articles } \\
\text { in the area of Technology for Agricultural Operations. The rationale for } \\
\text { using this database was based on its extensive coverage of journal articles } \\
\text { almost reaching } 22,800 \text { titles from over } 5000 \text { international publishers, } \\
\text { including coverage of approximately } 21,950 \text { peer-reviewed journals on } \\
\text { different areas }\end{array}$ \\
\hline Quality control & $\begin{array}{l}\text { Inclusion Criteria: To ensure quality, the review considered only published } \\
\text { peer-reviewed journal (including articles in press) by selecting the 'Arti- } \\
\text { cle' option from the Document Type option } \\
\text { Exclusion Criteria: Grey literature and other document types such as confer- } \\
\text { ence articles, trade publications, books series, book or book chapter, and } \\
\text { editorials were omitted }\end{array}$ \\
\hline Publication year & $\begin{array}{l}\text { Inclusion Criteria: The selected articles were published only between } 1984 \\
\text { and early 2020, in order to cover the whole transition from AgriTech to } \\
\text { AI-driven AgriTech approaches }\end{array}$ \\
\hline Publication Language & $\begin{array}{l}\text { Inclusion Criteria: Only articles published in the English language were } \\
\text { considered } \\
\text { Exclusion Criteria Articles published in any other languages were not } \\
\text { considered }\end{array}$ \\
\hline Types of publication articles & $\begin{array}{l}\text { Inclusion Criteria The selected articles were only empirical-based (i.e. case- } \\
\text { study, survey, results, analytical, etc.), models and conceptual papers } \\
\text { Exclusion Criteria: Review papers were excluded; however, these studies } \\
\text { were used in Stage } 1 \text { (to define the aim and objectives and the proposal) }\end{array}$ \\
\hline Article suitability review & $\begin{array}{l}\text { Inclusion Criteria: Article suitability process was conducted by ensuring } \\
\text { that selected articles contained several key phrases throughout the paper, } \\
\text { including, title, abstract, keywords and thereafter the whole paper. This } \\
\text { process focuses on those section(s) that explicitly referred to Agricultural } \\
\text { Technology and Operations }\end{array}$ \\
\hline Finalising articles & $\begin{array}{l}\text { Finalising article suitability for the review was done by reading the full } \\
\text { remaining article for essential research perspective and manuscripts } \\
\text { withempirical data. This process ensured the alignment between the } \\
\text { selected articles and the research review objectives }\end{array}$ \\
\hline
\end{tabular}
selected articles and the research review objectives

synthetically by searching for relevant articles through the Scopus database (Delbufalo 2012). In order to identify the relevant articles through the Scopus Database, the following keywords search criteria was used following the conditions 2, 3 and 4 of Table 2. This process resulted in 9951 publications, of which 543 were left as relevant after filtering according to the barring conditions.

A title and abstract analysis were thereafter conducted on the extracted articles based on the conditions 5 and 6 . At the end of the process, 205 articles were considered for further investigation (Table 3). Finally, the authors followed the quality criteria matrix as adopted by Pittaway et al. (2004). In this step, the selected 205 articles (Appendix II -included studies) were further scanned through the criteria highlighted in conditions 6 and 7. Besides extracting data related to Q1, Q2 and Q3, the descriptive investigation also produced graphs and tables designed to contain the yearly publications, geographical regions of where studies were conducted, the journal outlets and the various AIdriven solutions published in AgriTech research for all 205 articles (Appendix I- publication demographics). 
Table 3 The search process and results

\begin{tabular}{ll}
\hline Search process & \\
\hline Electronic database search & 9840 articles \\
Hand search & 76 articles \\
Citation search & 35 articles \\
Total & 9951 articles \\
Title and abstract review excluded $(n=9408)$ & \\
Total & 543 articles \\
Full text analysis excluded $(n=338)$ & \\
Total & 205 journal articles
\end{tabular}

\subsection{Demographics of the selected studies}

The included research studies of the last decades with a focus on AgriTech, present an evolving rise of AI-driven solutions for the agricultural stakeholders. The potential value of any AgriTech interventions can appear through the application of multiple advanced solutions that could be applied in the farming field. Agricultural stakeholders can apply the AgriTech solutions for processing a large volume of multi-form data and information into meaningful knowledge. There are multiple opportunities nowadays for agricultural stakeholders to apply AgriTech interventions for everyday farming operations, however, in order these interventions to be successful, advanced solutions are required to transform the farming operations in AI-driven approaches. The review of the studies in the field indicated that the top three most applied solutions in the AgriTech research (Fig. 1) consist of AI-driven solutions and they are namely, Machine Learning (ML), Modelling and Simulation, and Data Analytics.

The key journal outlets where the studies in the field of AgriTech and AI have been published appear in Fig. 2.

Many studies have been published in the Computers and Electronics in Agriculture outlet $(C=48)$. Unsurprisingly, the findings highlight the majority of the AI-driven AgriTech studies have been published in technical and agriculture-based outlets, such as

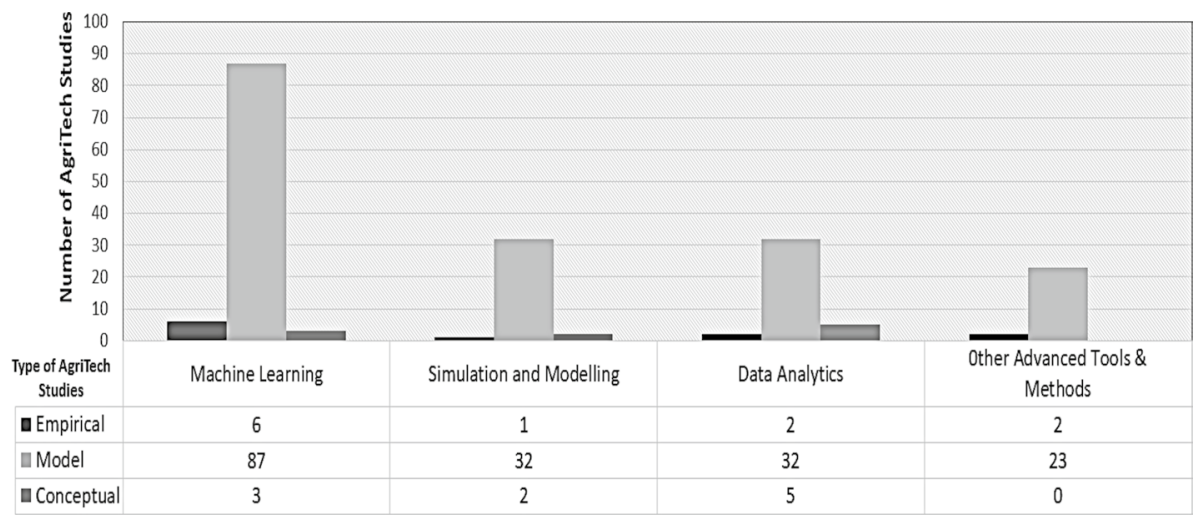

Fig. 1 Number and type of AI-driven AgriTech studies 


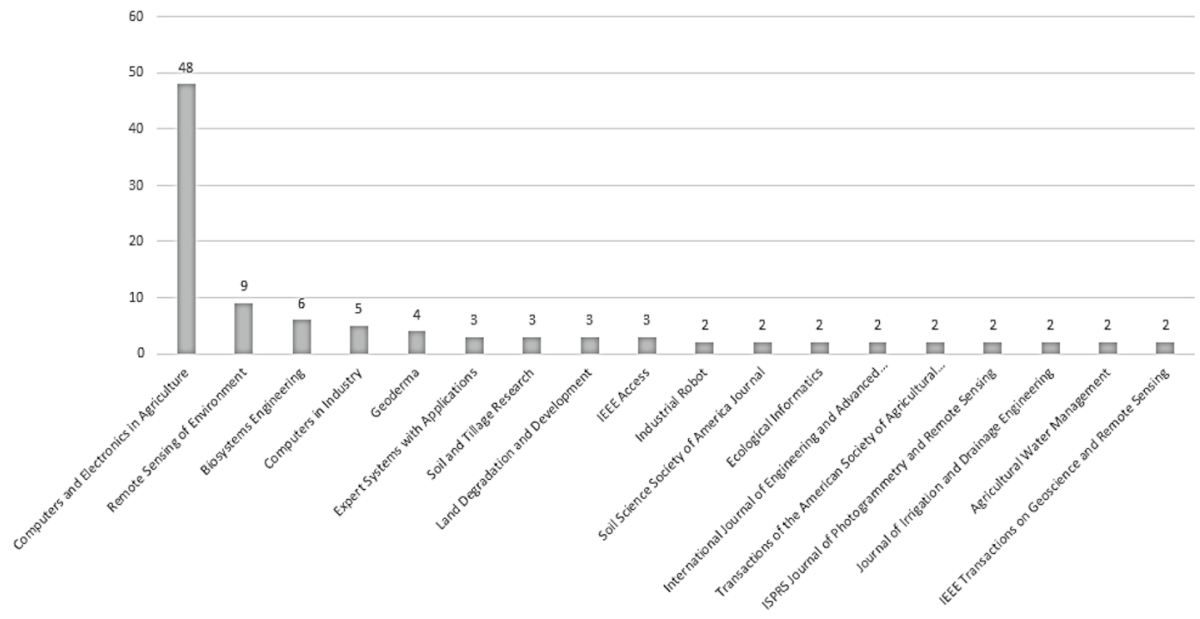

Fig. 2 Journals publishing AgriTech research

Biosystems Engineering and Remote Sensing of Environment. There is clear evidence to highlight the need for more research to be published in business, operations and information technology and systems management journals (except a Special Issue in Computers in Industry, where 5 studies were published in 2019) that allows exploring organisational and business efficiency-related issues of applying AgriTech.

The yearly studies published in the field of AI-driven AgriTech (Fig. 2) highlight an evolving interest in the field, with the most significant number of publications recorded for the year 2019 (with $\mathrm{C}=40,19.6 \%$ ), followed by years 2017-18 (with $\mathrm{C}=28$ and 27, 13\%).With fewer publications (i.e. below the 10 mark) were recorded from 2015 and a range of one and two articles between 1984 and 2000. Figure 1 below illustrates a rise in the number of journal articles in the AgriTech and AI research area from 2015 onwards until 2019, which is still evolving even in early 2020.

An initial screening of the identified studies revealed three interesting directions of the AgriTech Research:

1. The AgriTech studies are presenting AI-driven solutions from a technical perspective. However, there is a low number of conceptual and empirical studies (Fig. 1 -methodological approaches in the studies).

2. The AgriTech research is flourishing in mostly engineering and biosciences fields, with a lack of research in the field of operations and management (Fig. 2- publication outlets)

3. There is an evolving interest in AgriTech research in the last decade (Fig. 3 -yearly publications).

The demographics of the identified studies show the awareness and importance of this area among the academic community, practitioners, and even governments worldwide. Despite the increase in the number of articles on disruptive technologies for Agriculture, AI-driven AgriTech research is still in infancy, especially in terms of conceptual but also empirical studies. The research domain requires further in-depth conceptual as well as empirical studies, especially case study and survey-based research to explain 


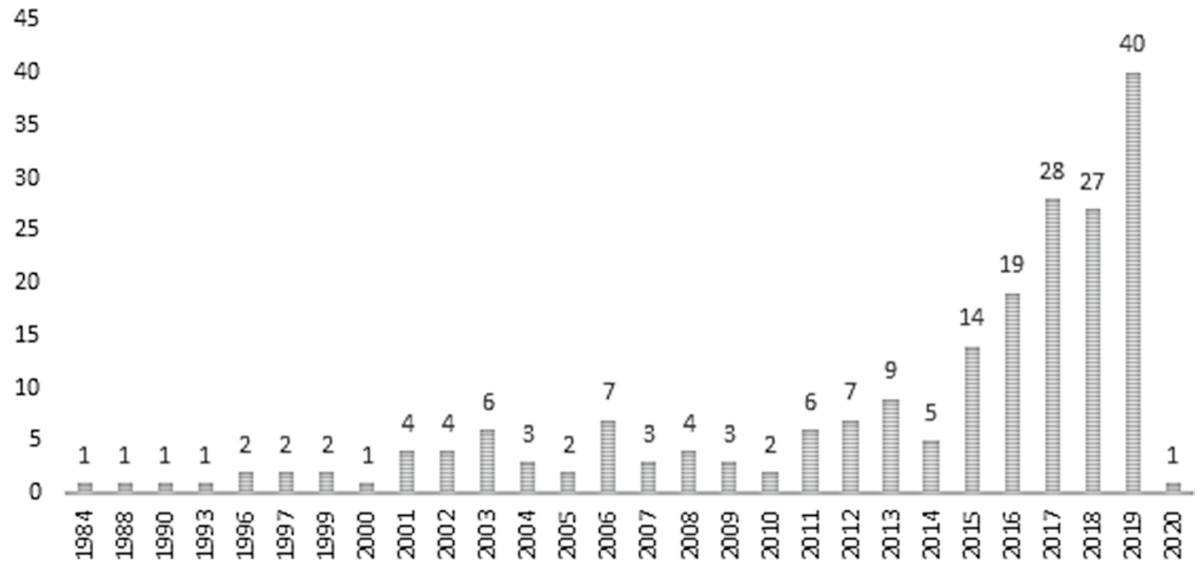

Fig. 3 Publications per year in the field of AgriTech

the implication and the potential social and industrial change and transformation (from business and operations perspectives).

\section{Synthesis of the AgriTech operations and applications}

The systematic review revealed various types of AgriTech in the analysed studies based on the representative aspects of the disruptive technology which is applied and described in each study. The identification of the types of AgriTech was built initially from the framework of Tsolakis et al. (2019), where three categories were defined according to the aspects of the specific technological application (physical, cyber, and cyber-physical). However, the research synthesis provided here expands the typology of Tsolakis et al. (2019) by scoping the studies on those on AI-driven AgriTech and defining the application type by operation area and the operational challenges that each category could support.

The categorisation in application types by operation area supports future directions for Operations Management by expanding the scope to an operations-oriented and processbased approach. The physical AgriTech application types are defined as the disruptive technologies for agricultural operations which can replace not only human labour tasks (e.g. robotic machinery, irrigation systems etc.) but also present physical features as the "hardware" of AgriTech, mostly this category refers to machinery and tools for agricultural tasks. On the other hand, the cyber aspects of AgriTech appear as applications which are mostly platform-software related and have a strong link with data analytics and decision support systems for agricultural operations whereas there is also a third category which is the combination of the two previous, the cyber-physical application area, which refers mostly to smart agricultural machinery and/ or robotics for the farm which include the hardware and the software for data analysis and predictive/prescriptive tailored decision-making, advice and recommendations. The cyber-physical applications have been developed within the last decade and follow the design and production patterns of the fourth industrial revolution applying disruptive technologies and AI techniques in the farming field. 


\subsection{AgriTech physical aspects per operation type and application area}

The Physical AgriTech aspects can be categorised and related to water operations, aerial operations, land operations and a combination of them based on their relevance with plants or animals (livestock). Table 4 shows the different AgriTech physical applications per operation type, application area and the associated challenges of the agricultural sector addressed by each solution.

Our analysis revealed the existence of only one study for physical aerial operations and the non-existence of water-based physical operations. In terms of studies providing context around the physical aerial operations, Radcliffe et al. (2018) focussed on the tree canopy and sky of an orchard row to be used by an autonomous vehicle platform to navigate through the centre of the tree rows. The research studies on AgriTech physical aspects mostly consider land operations on both plant and animal applications and their implementation using a variety of AgriTech tools and techniques such as satellite imagery, surveillance systems, agricultural machinery, field training, robots, and algorithms for machine learning and data processing.

In terms of the physical applications on plants, Kussul et al. (2017) used architecture to classify land cover and crop types through multi-temporal multi-source satellite imagery (deep learning). Studies as the one of Ennouri et al. (2019) discussed the importance of remote sensing technology, while the study of Seelan et al. (2003) is extending the context of remote sensing and implements a learning community approach for educating farmers with the associated technologies (field training). Other approaches of remote sensing imagery technologies in studies about physical AgriTech for land and aerial operations, present training algorithms to explore image processing techniques (Pydipati et al. 2006) for plant colour features differentiation (data analytics, algorithm). Some studies also show multiple irrigation mapping algorithms through machine learning techniques (Ozdogan and Gutman 2008), but also odometry robotic systems for imagery collection (Ericson and Åstrand 2018). Robotic applications for land surveillance appear in studies such as those of Ko et al. (2015) that presented a mobile robotic platform for agricultural applications), Edan et al. (1993) presented a robot harvester for melons using 3-D, real-time animation, Bayar (2017) developed an autonomous detection mobile robotic system of tree trunks, and

Table 4 AgriTech physical aspects per operation type and application area

\begin{tabular}{llll}
\hline Operation type & \multicolumn{2}{l}{ No. of studies per application area } & Challenges addressed by AgriTech solution \\
\cline { 2 - 3 } & Plant & Animal (Livestock) & \\
\hline Water & 0 & 0 & Tree condition checking \\
Aerial & 1 & 0 & Land and crop classification \\
Land & 11 & 3 & Land \& animal surveillance \\
& & Farmer education \\
& & Plant condition assessment \\
& & Irrigation mapping \\
& & Crop harvesting \\
& & Insect infestations assessment \\
& & Automated feeding of animals \\
& & Health assessment of animals \\
& & Environmental parameters monitoring \\
\hline
\end{tabular}


Kounalakis et al. (2019) with robotic weed recognition for grasslands. From these applications various benefits were archived such as reduced picking time of crops, increase of harvest efficiency, and faster detection of plant health issues.

Regarding the physical aspects of AgriTech in animal-related application areas, the studies focus on automated feeding technologies for pregnant sows (Manteuffel et al. 2011) and surveillance systems for social interaction monitoring in dairy stalls of cows (Guzhva et al. 2016), behaviour and living condition monitoring through an animal-mounted sensor, and automatic surveillance intelligent systems to automatically and continuously monitor the health animals (Yazdanbakhsh et al. 2017). Also, one study with a combination of land, water, and aerial operations was identified (Mesas-Carrascosa et al. 2015), where an opensource hardware system is presented for monitoring different environmental parameters.

\subsection{AgriTech cyber aspects per operation type and application area}

The AgriTech cyber aspects can be categorised into three forms: analytics, virtual/simulation, and algorithmic-based on the different types of tools and techniques applied (which will be explained further in a following designated section). These have been further classified in water, aerial, land operations or a combination of them as well as in terms of their application on animals or plants (see Table 5).

In the analytics categorisation, research directions are often focussed on water applications on plants and with combinations of soft-computing methods, as well as simulations and algorithms to improve the planning and management of water resources and to detect

Table 5 AgriTech cyber aspects per operation type and application area

\begin{tabular}{|c|c|c|c|c|c|c|c|}
\hline \multirow[t]{3}{*}{ Operation type } & \multicolumn{6}{|c|}{ No. of studies per application area } & \multirow{3}{*}{$\begin{array}{l}\text { Challenges addressed by AgriTech } \\
\text { solution }\end{array}$} \\
\hline & \multicolumn{2}{|c|}{$\begin{array}{l}\text { Analytics } \\
\text { platforms }\end{array}$} & \multicolumn{2}{|c|}{$\begin{array}{l}\text { Virtual/simu- } \\
\text { lation }\end{array}$} & \multicolumn{2}{|c|}{$\begin{array}{l}\text { Proposed } \\
\text { algorithms }\end{array}$} & \\
\hline & Plant & Animal & Plant & Animal & Plant & Animal & \\
\hline Water & 3 & 4 & 2 & 0 & 3 & 1 & $\begin{array}{l}\text { Irrigation planning and management } \\
\text { Chemicals detection } \\
\text { Automated resource collection from } \\
\text { animals } \\
\text { Climate control of animals housing } \\
\text { Water resources allocation } \\
\text { Soil assessment } \\
\text { Animal condition analysis }\end{array}$ \\
\hline Aerial & 4 & 0 & 0 & 0 & 0 & 0 & $\begin{array}{l}\text { Image processing for enabling precision } \\
\text { agriculture } \\
\text { Emissions modelling } \\
\text { Air temperature estimation } \\
\text { Yield classification }\end{array}$ \\
\hline Land & 4 & 1 & 3 & 1 & 7 & 3 & $\begin{array}{l}\text { Crop \& climatic conditions assessment } \\
\text { Animal behaviour prediction } \\
\text { Animal disease control }\end{array}$ \\
\hline Combination & 4 & 1 & 1 & 0 & 3 & 1 & $\begin{array}{l}\text { Yield optimisation } \\
\text { Natural resource availability assessment } \\
\text { Assessment of soil changes and their } \\
\text { implications }\end{array}$ \\
\hline
\end{tabular}


chemicals in the water. For example, Gocic et al. (2015) analysed different soft-computing methods, i.e. genetic programming (GP), support vector machine-firefly algorithm (SVMFFA), artificial neural network (ANN), and support vector machine-wavelet (SVM-Wavelet) to forecast reference evapotranspiration (ET0) which is used for planning and managing water resources in agriculture. While, Wang et al. (2006) simulated agriculture derived groundwater nitrate pollution patterns using the artificial neural network (ANN) technique, and Brumbelow and Georgakakos (2007) presented an application of physiologically based crop models to near-optimisation of "planning-level' irrigation schedules.

Studies using analytics in water applications for animals use a combination of simulation, optimisation and lab experiments. Halachmi (2009), for example, simulated the hierarchical order and cow queue length in an automatic milking system. Another example appears in the study of Aerts and Berckmans (2004), where a virtual chicken (VirChick) was developed for computer-aided design and engineering of climate controllers for poultry house. On a similar note, Chen et al. (2016) formulated a deterministic optimisation model to alleviate the impact of seasonal drought, which allocates available irrigation water resources to maximise annual returns in a reservoir-pond irrigation system. In the field of animal applications, O'Conell et al. (2015) analysed the animal conditions through artificial insemination in a lab environment.

AgriTech aerial analytics applications on plants are considering autonomous vehicles, meta-models, and image features capturing methods. Several studies used analytics for non-rigid image feature matching in precision agriculture via probabilistic inference with regularisation techniques (e.g. Yu et al. 2017), and meta-models for complex environmental and ecological processes over large geographic areas for emissions modelling of N20/ sland, climate (e.g. Perlman et al. 2014). Other studies, such as the study of Sanikhani et al. (2018), analysed the design and application of data-intelligent models for air temperature estimation without climate-based inputs using geographic factors. While in Radcliffe et al. (2018), the authors used an autonomous vehicle platform guided by machine vision system for tree canopy and sky of an orchard row.

There are numerous studies about analytics applications on land for plants that use a wide range of AgriTech, such as mixed spectral responses, neural networks, fuzzy logic, and index development. In this categorisation, some studies include approaches presenting training methods for vector machines (Foody and Mathur 2006), neural networks in combination with fuzzy techniques in the field of agro-ecological modelling (Schultz and Wieland 1997), presence-only geographic species distribution models, i.e. MaxEnt for agricultural crop suitability mapping (Heumann et al. 2011), and IoT- cloud-enabled measurement indexes for temperature and humidity assessment of crops (Mekala and Viswanathan 2019).

A combination of aerial, water and land application studies that used analytics for land and animals adopted a wide range of AgriTech applications. Some of these AgriTech applications are simulation models in combination with geographic information systems and optimisation, as well as algorithms with analytics. For example, McKinion et al. (2001) investigated the use of precision agriculture in combination with simulation models, and geographic information systems in a cotton production system to optimise yields while minimising water and nitrogen inputs. Other studies in the same categorisation evaluated the future impact of soil degradation using simulation and optimisation (Sonneveld and Keyzer 2003). At the same time, other studies used innovative unmanned airborne vehicles to visualise and quantify soil physical changes and their influence on surface morphology at submillimetre resolution (Kaiser et al. 2018) and identify the yield-limiting factors for farmers using real crop data (Paz et al. 2002). 
With regards to simulation techniques, the analysis revealed the existence of two studies that used simulation for water and land applications. Specifically, the interest of simulation models is about the agricultural water drainage challenge at the beginning of the cropping season (Jury et al. 2003), and the combination of unsaturated flow and groundwater (Kumar and Singh 2003).

There is also a stream of literature discussing the simulation models problems theoretically as population dynamics and population genetics of $\mathrm{H}$. zea in mixed cropping systems (Storer et al. 2003), and the effects of tillage and traffic on crop production in dryland farming systems (Li et al. 2008). While the study of Luecke (2012) developed a virtual reality interface that could be used in operating a combine when harvesting virtual crops. Other simulation models are presented for soil-plant-atmosphere in order to examine the influence of a winter cereal rye cover crop on nitrate-N losses (Feyereisen et al. 2007).

There is a wide range of algorithmic models presented in the reviewed studies for the improvement of water efficiency, optimisation of irrigation planning, and assessment of drainage. Such studies show stochastic dynamic programming models (SDPM) to analyse a farmer's optimal investment strategy to adopt a water-efficient drip irrigation system or a sprinkler irrigation systems (Heumesser et al. 2012), soil and assessment tool algorithms to relate drainage volume to water table depth (Moriasi et al. 2011), and physiologically based crop models to near-optimisation of "planning-level" irrigation schedules (Brumbelow and Georgakakos 2007). Only one study was identified with algorithmic water-based applications on animals which used neural network applications to intelligent data analysis in the field of animal science (Fernández et al. 2006).

There are a plethora of studies that developed AgriTech algorithmic applications for land and plants. Some of the studies presented neural networks (Moshou et al. 2001) for the classification of crops and weeds, and hyperspectral imagery for defection segmentation using classifiers based on Artificial Neural Networks and Decision Trees (Gómez-Sanchis et al. 2012). While studies such as those of Richards et al. (2009) considered the knowledge content of farmer seed systems in the light of a distinction drawn in artificial intelligence research between supervised and unsupervised learning and suggested an alternative approach supported by functional genomic analysis. On a similar note, but using the fuzzy logic approach for decision systems, the review identified a few studies for decisions around specific nitrogen fertilisation (Papadopoulos et al. 2011), hybrid learning of fuzzy cognitive maps for sugarcane yield classification (Natarajan et al. 2016), and flexible irrigation scheduling for different irrigation districts and cases (Yang et al. 2017).

Algorithmic land applications on animals are not that frequent, and most of the studies towards this direction present mostly machine learning techniques and computer programming. In this category, there are research projects applying machine learning techniques to detect oestrus in dairy cows (Scott Mitchell et al. 1996), convolutional neural networks for body condition estimation on cows from depth images (Rodríguez Alvarez et al. 2018), and computer programs for the prototypical knowledge base for cows (Oltjen et al. 1990).

Combinations of water and land algorithmic applications on plants are focusing on soil forecasting and planning. In this category, Keller et al. (2007) developed a new model, 'SoilFlex-LLWR', which combines a soil compaction model with the least limiting water range (LLWR) concept. Also, there are models for monthly soil moisture forecasting (Prasad et al. 2018), and machine learning assessments of soil drying for agricultural planning (Coopersmith et al. 2016). While algorithms and models about various applications related to animal and livestock conditions and welfare are very limited. In the few studies of that category, there are examples of studies such as Gonzalez et al. (2015) that developed an algorithm for unsupervised behavioural classification of electronic data collected 
at high frequency from collar-mounted motion and GPS sensors in grazing cattle for automatic and real-time monitoring of behaviour with a high spatial and temporal resolution.

\subsection{AgriTech cyber-physical applications}

AgriTech cyber-physical applications refer to applications that combine physical aspects with cyber aspects of AgriTech, e.g. smart tractors, drones connected with sensors at the field, and a number of smart devices for applying AI for agricultural processes. Table 6 presents a summary of the AgriTech cyber-physical applications per application area.

There are numerous studies about AgriTech analytical cyber-physical applications for tasks related to land and plants that develop platforms, algorithms for robots, and decision support systems. These applications are presented as:

- A suboptimal path for agricultural mobile robots combining neural network methods and genetic algorithms (Noguchi and Terao 1997);

- a private Internet of Things (IoT) enabled platform for the research in precision agriculture and ecological monitoring domains (Popović et al. 2017);

- a decision-making system for intelligent chemical control (Guedes et al. 2013);

- a research data collection platform for ISO 11,783 compatible and retrofit farm equipment to control agricultural operations on the farm (Backman et al. 2019);

- a methodology for olive oil traceability to interconnect field and industry to share information (Bayano-Tejero et al. 2019).

There are also several studies about AgriTech cyber-physical analytical applications on land and animals that used sensors, imagery, and algorithms. For example, Manteuffel et al. (2011) implemented a call feeding for pregnant sows which is a modular extension of a conventional electronic feeder and communicates via a network. Another study (Sakai et al. 2019) classified goat behaviours using 9-axis multi-sensor data and a machine learning algorithm. In studies such as Ivushkin et al. (2019), the authors presented a method for livestock mapping of pastured to produce spatial-temporal consistent maps, while Bishop et al. (2019) developed a multi-purpose livestock vocalisation algorithm with machine learning techniques for a continuous acoustic monitoring system. Combination studies about land and water cyber-physical

Table 6 AgriTech cyber-physical applications per application area

\begin{tabular}{|c|c|c|c|c|c|c|c|}
\hline \multirow[t]{3}{*}{ Operation type } & \multicolumn{6}{|c|}{ No. of studies per application area by technique } & \multirow{3}{*}{$\begin{array}{l}\text { Challenges addressed by } \\
\text { AgriTech Solution }\end{array}$} \\
\hline & \multicolumn{2}{|c|}{$\begin{array}{l}\text { Analytics plat- } \\
\text { forms }\end{array}$} & \multicolumn{2}{|c|}{ Virtual/simulation } & \multicolumn{2}{|c|}{$\begin{array}{l}\text { Proposed algo- } \\
\text { rithms }\end{array}$} & \\
\hline & Plant & Animal & Plant & Animal & Plant & Animal & \\
\hline Water & 0 & 0 & 0 & 0 & 1 & 0 & Mimicking crop irrigation \\
\hline Aerial & 1 & 0 & 1 & 0 & 1 & 0 & $\begin{array}{l}\text { Insect mapping on crops } \\
\text { Plant analysis }\end{array}$ \\
\hline Land & 5 & 3 & 2 & 1 & 4 & 3 & $\begin{array}{l}\text { Traceability enhancement } \\
\text { Chemical control } \\
\text { Animal feeding } \\
\text { Animal condition analysis } \\
\text { Livestock mapping }\end{array}$ \\
\hline Combination & 2 & 0 & 0 & 0 & 0 & 0 & Soil quantification \\
\hline
\end{tabular}


analytics for plants are using drones and imagery technologies for soil quantification. Kaiser et al. (2018) used unmanned airborne vehicle to visualise and quantify soil physical changes and their influence on surface morphology at submillimetre resolution. Another research direction quantified soil pore characteristics using a high-resolution X-ray CT scanner linked to soil friability assessed using the drop shatter method (Munkholm et al. 2012). The review indicated that analytics applications of AgriTech in aerial studies of cyber-physical systems for plants are very limited, while for animals are absent. In this research category, there are studies, for example, that present Unmanned Aerial Vehicles (UAVs) to collect imagery about sunflower and maze crops to solve the problem of weed mapping for precision agriculture and proposed a method for pattern selection (Pérez-Ortiz et al. 2016).

Studies about cyber-physical simulation applications focussing on land and plants use Discrete Element Model (DEM) to simulate a deep tillage tool and its interaction with soil to address the stratified soil layers in agricultural fields (Zeng et al. 2017), and simulation of a comprehensive framework that transforms data acquisition platforms and makes possible the "plug-and-play" connection of various sensors (Fernandes et al. 2013). Only one study was identified that considered aerial cyber-physical application using simulation. To be more precise, the study of (Andersen et al. 2005) explored the potential of using areabased binocular stereo vision for three-dimensional (3-D) analysis of single plants and estimation of geometric attributes such as height and total leaf area.

Studies about algorithmic cyber-physical applications on land and plants are focussing on machine learning algorithms and robotics. Such studies present automatic observation systems for wheat heading stage based on computer vision (Zhu et al. 2016) remotely assessing soil conditions (Coopersmith et al. 2016), spiking neural networks (SNNs) for remote sensing spatiotemporal analysis of image time series(Bose et al. 2016), robotic weed recognition applications for precision agriculture in grasslands (Kounalakis et al. 2019).

Cyber-physical algorithms for animals consider machine learning techniques and suggested new algorithmic functions. An example of these is a supervised machine learning technique to classify cattle behaviour patterns recorded using collar systems with 3-axis accelerometer and magnetometer, fitted to individual dairy cows to infer their physical behaviours (Dutta et al. 2015). Cattle behaviours were also classified upon the "one-vs-all" framework (Smith et al. 2016). Studies about conditions for pig development used RGB-D computer vision and machine learning, physical (images from pigs), algorithm (machine learning and RGB-D computer vision) to estimate the muscularity of live pigs (Alsahaf et al. 2019). Only one study about cyber-physical water application on plants was found, while studies about water-based applications on animals are non-existent. On that basis, Viani et al. (2017) developed an innovative methodology based on Fuzzy Logic (FL) to mimic the farmers' experience and best practices for crop irrigation. No cyber-physical studies about aerial applications on animals and plants were found.

\section{Future considerations and the way forward}

The applications of AI and disruptive technologies in Agricultural Operations are providing new ways to increase the yield, optimise the processes and enhance the sustainability of agricultural production (Miranda et al. 2019; Wolfert et al. 2017). The focus of AgriTech and smart farming appears mostly around AI-driven approaches and agricultural data analytics platforms collecting data in order to provide planting advice, tailored recommendations and a general sense-making process of the data stemming from the fields (Boshkoska et al. 2019; Miranda 
et al. 2019). The systematic review of AgriTech research has unravelled multiple opportunities for disruptive technologies based on AI-techniques and applications, with a focus mostly on creating value for the Agricultural Sector (Boshkoska et al. 2019; Tzounis et al. 2017).

Through the use of AgriTech and applications of AI, the Agricultural Sector can operate and transform the conventional practices through data analytics and machine learning techniques, which are able to provide targeted advice on each case (Kouadio et al. 2018). The use of the data can envisage competitive advantage even by itself not only for the farmers but also for the whole Agricultural Sector. By collecting data from the field, the farmer can gain knowledge according to each case's requirements, as well as follow prescriptions in advance and provide them as a solution to broader farming problems (Kale and Sonavane 2019; Kouadio et al. 2018; Renuka and Terdal 2019; Tatapudi and Suresh Varma 2019). For instance, this will help farmers in mapping the fields, monitor crop canopy remotely, check for anomalies and take precautionary actions in order to implement more proactive, resilient and sustainable agricultural practices.

AI-driven AgriTech is developed from cross-section disciplines involving a variety of smart and data-intensive approaches, disruptive technologies- spanning from smart devices, sensors, and big data to drone technology and robotics (Miranda et al. 2019; Tsolakis, Bechtsis, and Bochtis 2019). Smart monitoring, irrigation, images and temperature from the field, as well as the soil or livestock conditions, to name a few, can provide a pool of data for tailored recommendations to the farmer and any interested parties (Karim et al. 2017; Manoj Athreya et al. 2019; Tsolakis, Bechtsis, and Bochtis 2019). Data analytics, machine learning, robotics, or any other AI technique applied in the farm through automated practices could provide recommendations, warnings, or even efficiency monitoring and enhance the farming operations, suggesting opportunities for Agriculture to be viable again (Corallo et al. 2018).

The data evolution and cutting-edge, disruptive technologies have shifted the paradigm of conventional and modern agriculture and farming to smart and intelligent approaches. Following data-driven analytical technologies and high-performance computing, the AI context was reshaped and re-emerged in the last decade, creating numerous opportunities for smart and data-intensive solutions in the AgriTech domain. Hence, AgriTech could be defined in today's Agricultural context as the use of data-driven smart technologies and analytical methods for enhancing the farming practices, operations and decision-making in order to achieve in multiple forms and ways the economic efficiency and environmental sustainability of the Agricultural field.

The authors of this research would like to highlight that the findings of this systematic review should be considered within the context of its methodological limitations. It is to be noted that In order to be thorough and conduct an exhaustive search in an SLR research, other notable databases need to be used which helps with being able to cross-check as well as explore in-depth the area of interest. So, the use of only one database (i.e. Scopus) may be considered as a limitation in this research. The authors followed a strict review protocol to conduct a comprehensive search through the Scopus database to mitigate the risks associated with relying on a single database. A summary of the implications of AI-driven AgriTech applications and the associated future research required in the field of operations is highlighted in Table 7.

\section{Implications to practice}

Triggered by the urgency to deal with food security, the digital disruption of Agriculture is unique by its roots and therefore the motivation to adopt AgriTech should be genuine from farmers (CEMA-European Agricultural Machinery 2017). While 
Table 7 Future considerations for AgriTech research

\begin{tabular}{|c|c|}
\hline Area of research & Future research considerations \\
\hline $\begin{array}{l}\text { Farm management } \\
\text { cycle and opera- } \\
\text { tions }\end{array}$ & $\begin{array}{l}\text { How Virtual and Augmented Reality can enhance the applications of precision } \\
\text { agriculture? } \\
\text { How can Smart Indoor Vertical Farming evolve and support farming production? } \\
\text { How can future AgriTech innovations reshape the farming processes? }\end{array}$ \\
\hline Analytics platforms & $\begin{array}{l}\text { How can farming analytics (Farm to Fork Analytics) contribute to sustainability chal- } \\
\text { lenges? } \\
\text { How can Farming Analytics provide an advantage to small, medium and larger farms? }\end{array}$ \\
\hline Sensor technology & $\begin{array}{l}\text { How can IoT-enabled platforms improve farming production for the sustainability of } \\
\text { AgriFood sector? } \\
\text { How can IoT-enabled regenerative agriculture evolve the next decade? } \\
\text { What are the required data sharing policies in order to ensure privacy and competitive } \\
\text { advantage for the operations of each farm? }\end{array}$ \\
\hline Robotics & $\begin{array}{l}\text { What are the next AI and Robotics Ventures (ARV) for socially and environmentally } \\
\text { responsible farming? } \\
\text { What is the role of AgriTech robots in the new agricultural operations? } \\
\text { How can 3D mapping and monitoring contribute to the sustainability goals of each } \\
\text { farm? } \\
\text { How can hybrid (aerial-ground) drones improve operation management in an } \\
\text { unmanned way for agricultural monitoring? } \\
\text { How can drones be used for remote agricultural operations in crisis situations? } \\
\text { How can hybrid drones and manned aviators collaborate for precision agriculture? }\end{array}$ \\
\hline
\end{tabular}

farmers are keen on applying innovative and emerging technologies (e.g. in previous centuries and decades early adopters started with the wheel, tractors, fertilisers etc.) the industrial revolution resulted in large-scale farming and massive production at any cost, in a socially and environmentally unsustainable, and economically inefficient way (Yahya 2018; Zambon et al. 2019). Despite the challenges, already there is a new range of motivated farmers and agricultural start-ups adopting disruptive technologies to manage their operations in digitalised and automated ways. Disruptive technologies in Agricultural Sector, often dubbed as AgriTech, can be widely used by a new generation of farmers but also Agripreneurs, a new category of farmer-entrepreneurs trialling AgriTech innovations for the farming field (Carayannis et al. 2018). Agripreneurs consist of a new breed of educated entrepreneurs who merge their knowledge and expertise on agriculture and farming with an acquired business and management approach in order to bridge the gap between farming practices and applied agribusiness principles. Among agribusiness principles, sustainability is becoming increasingly crucial for the success of Agrichains. Sustainable Agrichains are dealing with continued complexities of stakeholders' demands on Sustainable Development. As sustainability is becoming more complex, dealing with its challenges are also becoming challenging and costly for Agripreneurs. The initial pragmatic solution is to incorporate Agritech interventions to tackle the sustainablity challenges in Agrichains. Over the last decade, advances in Agritech solutions research have made a significant contribution towards the understanding and implementation of sustainablity criteria in farming and Agrichains.

In a nutshell, with the application of new AgriTech technologies, every farmer could potentially become an Agripreneur and a champion of sustainability in the near future. Thus, the role of Operations Management is vital to bridge the research gap between 
"Agricultural Technology" and "Sustainable Agricultural Operations" and equip the future generation of farmers-agripreneurs.

\section{Conclusions}

Drawing on the recent advances of disruptive technologies for agriculture the review provided interesting insight in the field of AI-driven AgriTech research. The synthesis of the literature can act as a normative reference for the Operations discipline when studying the thematic area of disruptive agricultural technologies. The key findings of this review in line with the initial three research questions are as follows:

- Key Types of Disruptive Technologies and Categories of AgriTech (Q1 and Q2): The analysis highlights that majority of the types of disruptive technologies in the agricultural sector can be categorised into three application areas. The first is (1) Physical AgriTech application type which highlights the use of machinery and tools for agricultural operations which can replace not only human labour tasks (e.g. robotic machinery, irrigation systems etc.) but also presents physical features as the "hardware" of AgriTech. The second is (2) Cyber AgriTech as applications which are mostly platform-software related and have a strong link with data analytics and decision support systems for agricultural operations. Finally, (3) Cyber-physical application area which mainly refers to the use of smart agricultural machinery and/ or robotics for the farm which include the hardware and the software for data analysis and predictive/prescriptive tailored decision-making, advice and recommendations.

- Role of AI applications in Agricultural Operations (Q3): The analysis highlighted that AI-driven AgriTech could disrupt Agricultural Operations and provide new ways of farming practices. There is still an open discussion around various implications and future considerations in the Operations field. The Operations scholars have a key role to play in future AgriTech research in order to define and efficiently design the operational context around AI-driven AgriTech.

The findings of the systematic review will assist both academics and practitioners with interest in the agricultural sector to develop new solutions based on the challenges identified in this paper. Also, it integrates multiple disciplines and approaches for different research fields (spanning from engineering, biotechnology, to data science, cognitive processes of decision-making, etc.). It is evident from the comprehensive review conducted that there is growing interest in the use of AI and data science to support the use of disruptive technologies; motivated to enhance productivity, reduce cost, integrate systems and, promote sustainable farming and food production practice.

\section{Appendix}

See Table 8 . 
Table 8 Details of the 205 included studies

Paper ID References

1 Foody GM, Mathur A (2006) The use of small training sets containing mixed pixels for accurate hard image classification: Training on mixed spectral responses for classification by a SVM. Remote Sens Environ 103:179-189. https://doi.org/10.1016/j.rse.2006.04.001

Kussul N, Lavreniuk M, Skakun S, Shelestov A (2017) Deep Learning Classification of Land Cover and Crop Types Using Remote Sensing Data. IEEE Geosci Remote Sens Lett 14:778782. https://doi.org/10.1109/LGRS.2017.2681128

Seelan SK, Laguette S, Casady GM, Seielstad GA (2003) Remote sensing applications for precision agriculture: A learning community approach. Remote Sens Environ 88:157-169. https:// doi.org/10.1016/j.rse.2003.04.007

Pydipati R, Burks TF, Lee WS (2006) Identification of citrus disease using color texture features and discriminant analysis. Comput Electron Agric 52:49-59. https://doi.org/10.1016/j.compa g.2006.01.004

Ozdogan M, Gutman G (2008) A new methodology to map irrigated areas using multi-temporal MODIS and ancillary data: An application example in the continental US. Remote Sens Environ 112:3520-3537. https://doi.org/10.1016/j.rse.2008.04.010

Bourennane H, Douay F, Sterckeman T, et al. (2010) Mapping of anthropogenic trace elements inputs in agricultural topsoil from Northern France using enrichment factors. Geoderma 157:165-174. https://doi.org/10.1016/j.geoderma.2010.04.009

Keller T, Défossez P, Weisskopf P, et al. (2007) SoilFlex: A model for prediction of soil stresses and soil compaction due to agricultural field traffic including a synthesis of analytical approaches. Soil Tillage Res 93:391-411. https://doi.org/10.1016/j.still.2006.05.012

Storer NP, Peck SL, Gould F, et al. (2003) Spatial Processes in the Evolution of Resistance in Helicoverpa zea (Lepidoptera: Noctuidae) to Bt Transgenic Corn and Cotton in a Mixed Agroecosystem: A Biology-rich Stochastic Simulation Model. J Econ Entomol 96:156-172

Rushton J, Thornton PK, Otte MJ (1999) Methods of economic impact assesment. OIE Rev Sci Tech 18:315-342. https://doi.org/10.20506/rst.18.2.1172

Matthews KB, Schwarz G, Buchan K, et al. (2008) Wither agricultural DSS? Comput Electron Agric 61:149-159. https://doi.org/10.1016/j.compag.2007.11.001

Berenstein R, Shahar OB, Shapiro A, Edan Y (2010) Grape clusters and foliage detection algorithms for autonomous selective vineyard sprayer. Intell Serv Robot 3:233-243. https://doi. org/10.1007/s11370-010-0078-z

Pérez-Ortiz M, Peña JM, Gutiérrez PA, et al. (2016) Selecting patterns and features for betweenand within- crop-row weed mapping using UAV-imagery. Expert Syst Appl 47:85-94. https:// doi.org/10.1016/j.eswa.2015.10.043

Bouma J, Stoorvogel J, Van Alphen BJ, Booltink HWG (1999) Pedology, precision agriculture, and the changing paradigm of agricultural research. Soil Sci Soc Am J 63:1763-1768

Munkholm LJ, Heck RJ, Deen B (2012) Soil pore characteristics assessed from X-ray microCT derived images and correlations to soil friability. Geoderma 181-182:22-29. https://doi. org/10.1016/j.geoderma.2012.02.024

Noguchi N, Terao H (1997) Path planning of an agricultural mobile robot by neural network and genetic algorithm. Comput Electron Agric 18:187-204

Minervini M, Abdelsamea MM, Tsaftaris SA (2014) Image-based plant phenotyping with incremental learning and active contours. Ecol Inform 23:35-48. https://doi.org/10.1016/j.ecoin f.2013.07.004

Gocić M, Motamedi S, Shamshirband S, et al. (2015) Soft computing approaches for forecasting reference evapotranspiration. Comput Electron Agric 113:164-173. https://doi.org/10.1016/j. compag.2015.02.010 tion of data from collars containing motion sensors in grazing cattle. Comput Electron Agric 110:91-102. https://doi.org/10.1016/j.compag.2014.10.018 
Table 8 (continued)

Paper ID References

19 Andersen HJ, Reng L, Kirk K (2005) Geometric plant properties by relaxed stereo vision using simulated annealing. Comput Electron Agric 49:219-232. https://doi.org/10.1016/j.compa g.2005.02.015

Moshou D, Vrindts E, De Ketelaere B, et al. (2001) A neural network based plant classifier. Comput Electron Agric 31:5-16. https://doi.org/10.1016/S0168-1699(00)00170-8

Dutta R, Smith D, Rawnsley R, et al. (2015) Dynamic cattle behavioural classification using supervised ensemble classifiers. Comput Electron Agric 111:18-28. https://doi.org/10.1016/j. compag.2014.12.002

McKinion JM, Jenkins JN, Akins D, et al. (2001) Analysis of a precision agriculture approach to cotton production. Comput Electron Agric 32:213-228. https://doi.org/10.1016/S0168 $-1699(01) 00166-1$

dos Santos Ferreira A, Matte Freitas D, Gonçalves da Silva G, et al. (2017) Weed detection in soybean crops using ConvNets. Comput Electron Agric 143:314-324. https://doi. org/10.1016/j.compag.2017.10.027

Gómez-Sanchis J, Martín-Guerrero JD, Soria-Olivas E, et al. (2012) Detecting rottenness caused by Penicillium genus fungi in citrus fruits using machine learning techniques. Expert Syst Appl 39:780-785. https://doi.org/10.1016/j.eswa.2011.07.073

Sonneveld BGJS, Keyzer MA (2003) Land under pressure: Soil conservation concerns and opportunities for Ethiopia. L Degrad Dev 14:5-23. https://doi.org/10.1002/ldr.503

Feng Y, Peng Y, Cui N, et al. (2017) Modeling reference evapotranspiration using extreme learning machine and generalised regression neural network only with temperature data. Comput Electron Agric 136:71-78. https://doi.org/10.1016/j.compag.2017.01.027

Maimaitijiang M, Ghulam A, Sidike P, et al. (2017) Unmanned Aerial System (UAS)-based phenotyping of soybean using multi-sensor data fusion and extreme learning machine. ISPRS J Photogramm Remote Sens 134:43-58. https://doi.org/10.1016/j.isprsjprs.2017.10.011

Yan L, Roy DP (2015) Improved time series land cover classification by missing-observationadaptive nonlinear dimensionality reduction. Remote Sens Environ 158:478-491. https://doi. org/10.1016/j.rse.2014.11.024

Kumar R, Singh J (2003) Regional water management modeling for decision support in irrigated agriculture. J Irrig Drain Eng 129:432-439. https://doi.org/10.1061/(ASCE)07339437(2003)129:6(432)

Schultz A, Wieland R (1997) The use of neural networks in agroecological modelling. Comput Electron Agric 18:73-90

Popović T, Latinović N, Pešić A, et al. (2017) Architecting an IoT-enabled platform for precision agriculture and ecological monitoring: A case study. Comput Electron Agric 140:255-265. https://doi.org/10.1016/j.compag.2017.06.008

ronment. IEEE Control Syst 21:8-12. https://doi.org/10.1109/37.954516
Cheng X, Zhang Y, Chen Y, et al. (2017) Pest identification via deep residual learning in complex background. Comput Electron Agric 141:351-356. https://doi.org/10.1016/j.compa g.2017.08.005

34 Richards P, De Bruin-Hoekzema M, Hughes SG, et al. (2009) Seed systems for African food security: Linking molecular genetic analysis and cultivator knowledge in West Africa. Int J Technol Manag 45:196-214

Mesas-Carrascosa FJ, Verdú Santano D, Meroño JE, et al. (2015) Open source hardware to monitor environmental parameters in precision agriculture. Biosyst Eng 137:73-83. https://doi. org/10.1016/j.biosystemseng.2015.07.005

Heumesser C, Fuss S, Szolgayová J, et al. (2012) Investment in Irrigation Systems under Precipitation Uncertainty. Water Resour Manag 26:3113-3137. https://doi.org/10.1007/s1126 9-012-0053-x 
Table 8 (continued)

Paper ID References

37 Viani F, Bertolli M, Polo A (2017) Low-Cost Wireless System for Agrochemical Dosage Reduction in Precision Farming. IEEE Sens J 17:5-6. https://doi.org/10.1109/JSEN.2016.2622244

38 Peres E, Fernandes MA, Morais R, et al. (2011) An autonomous intelligent gateway infrastructure for in-field processing in precision viticulture. Comput Electron Agric 78:176-187. https:// doi.org/10.1016/j.compag.2011.07.005

Sarangi A, Singh M, Bhattacharya AK, Singh AK (2006) Subsurface drainage performance study using SALTMOD and ANN models. Agric Water Manag 84:240-248. https://doi. org/10.1016/j.agwat.2006.02.009

Papadopoulos, Kalivas, Hatzichristos (2011) Decision support system for nitrogen fertilisation using fuzzy theory. Comput Electron Agric 78:130-139. https://doi.org/10.1016/j.compa g.2011.06.007

Morriss S, Massey C, Flett R, et al. (2006) Mediating technological learning in agricultural innovation systems. Agric Syst 89:26-46. https://doi.org/10.1016/j.agsy.2005.08.002

Scott Mitchell R, Sherlock RA, Smith LA (1996) An investigation into the use of machine learning for determining oestrus in cows. Comput Electron Agric 15:195-213. https://doi. org/10.1016/0168-1699(96)00016-6

Prasad R, Deo RC, Li Y, Maraseni T (2018) Soil moisture forecasting by a hybrid machine learning technique: ELM integrated with ensemble empirical mode decomposition. Geoderma 330:136-161. https://doi.org/10.1016/j.geoderma.2018.05.035

Belayneh A, Adamowski J (2013) Drought forecasting using new machine learning methods. J Water L Dev 18:3-12. https://doi.org/10.2478/jwld-2013

Delgado JA, Kowalski K, Tebbe C (2013) The first Nitrogen Index app for mobile devices: Using portable technology for smart agricultural management. Comput Electron Agric 91:121-123. https://doi.org/10.1016/j.compag.2012.12.008

Navon S, Mizrach A, Hetzroni A, Ungar ED (2013) Automatic recognition of jaw movements in free-ranging cattle, goats and sheep, using acoustic monitoring. Biosyst Eng 114:474-483. https://doi.org/10.1016/j.biosystemseng.2012.08.005

Kang M, Wang F-Y (2017) From parallel plants to smart plants: Intelligent control and management for plant growth. IEEE/CAA J Autom Sin 4:161-166. https://doi.org/10.1109/ JAS.2017.7510487

Zhu Y, Cao Z, Lu H, et al. (2016) In-field automatic observation of wheat heading stage using computer vision. Biosyst Eng 143:28-41. https://doi.org/10.1016/j.biosystemseng.2015.12.015

Valente J, Cerro JD, Barrientos A, Sanz D (2013) Aerial coverage optimisation in precision agriculture management: A musical harmony inspired approach. Comput Electron Agric 99:153-159. https://doi.org/10.1016/j.compag.2013.09.008

Heumann BW, Walsh SJ, McDaniel PM (2011) Assessing the application of a geographic presence-only model for land suitability mapping. Ecol Inform 6:257-269. https://doi. org/10.1016/j.ecoinf.2011.04.004

Fernandes MA, Matos SG, Peres E, et al. (2013) A framework for wireless sensor networks management for precision viticulture and agriculture based on IEEE 1451 standard. Comput Electron Agric 95:19-30. https://doi.org/10.1016/j.compag.2013.04.001

Yang JY, Huffman EC (2004) EasyGrapher: Software for graphical and statistical validation of DSSAT outputs. Comput Electron Agric 45:125-132. https://doi.org/10.1016/j.compa g.2004.06.006

Hassanien AE, Gaber T, Mokhtar U, Hefny H (2017) An improved moth flame optimisation algorithm based on rough sets for tomato diseases detection. Comput Electron Agric 136:86-96. https://doi.org/10.1016/j.compag.2017.02.026 for the retrieval challenges of dryland agricultural systems. Remote Sens Environ 186:105120. https://doi.org/10.1016/j.rse.2016.08.017 
Table 8 (continued)

Paper ID References

55 Basu S, Ganguly S, Nemani RR, et al. (2015) A Semiautomated Probabilistic Framework for Tree-Cover Delineation From 1-m NAIP Imagery Using a High-Performance Computing Architecture. IEEE Trans Geosci Remote Sens 53:5690-5708. https://doi.org/10.1109/ TGRS.2015.2428197

Coopersmith EJ, Cosh MH, Jacobs JM (2016) Comparison of in situ soil moisture measurements: An examination of the neutron and dielectric measurements within The Illinois Climate Network. J Atmos Ocean Technol 33:1749-1758. https://doi.org/10.1175/JTECH-D-16-0029.1

Vieira DAN, Dabney SM (2011) Modeling edge effects of tillage erosion. Soil Tillage Res 111:197-207. https://doi.org/10.1016/j.still.2010.10.007

Brumbelow K, Georgakakos A (2007) Determining crop-water production functions using yieldirrigation gradient algorithms. Agric Water Manag 87:151-161. https://doi.org/10.1016/j. agwat.2006.06.016

Fernández C, Soria E, Martín JD, Serrano AJ (2006) Neural networks for animal science applications: Two case studies. Expert Syst Appl 31:444-450. https://doi.org/10.1016/j. eswa.2005.09.086

Smith D, Rahman A, Bishop-Hurley GJ, et al. (2016) Behavior classification of cows fitted with motion collars: Decomposing multi-class classification into a set of binary problems. Comput Electron Agric 131:40-50. https://doi.org/10.1016/j.compag.2016.10.006

Bose P, Kasabov NK, Bruzzone L, Hartono RN (2016) Spiking Neural Networks for Crop Yield Estimation Based on Spatiotemporal Analysis of Image Time Series. IEEE Trans Geosci Remote Sens 54:6563-6573. https://doi.org/10.1109/TGRS.2016.2586602

Ko MH, Ryuh B-S, Kim KC, et al. (2015) Autonomous Greenhouse Mobile Robot Driving Strategies from System Integration Perspective: Review and Application. IEEE/ASME Trans Mechatronics 20:1705-1716. https://doi.org/10.1109/TMECH.2014.2350433

Natarajan R, Subramanian J, Papageorgiou EI (2016) Hybrid learning of fuzzy cognitive maps for sugarcane yield classification. Comput Electron Agric 127:147-157. https://doi. org/10.1016/j.compag.2016.05.016

Emmi L, Paredes-Madrid L, Ribeiro A, et al. (2013) Fleets of robots for precision agriculture: A simulation environment. Ind Rob 40:41-58. https://doi.org/10.1108/01439911311294246

Hameed IA, Bochtis DD, Sørensen CG, et al. (2013) Optimised driving direction based on a three-dimensional field representation. Comput Electron Agric 91:145-153. https://doi. org/10.1016/j.compag.2012.12.009

Johnen T, Boettcher U, Kage H (2012) A variable thermal time of the double ridge to flag leaf emergence phase improves the predictive quality of a CERES-Wheat type phenology model. Comput Electron Agric 89:62-69. https://doi.org/10.1016/j.compag.2012.08.002

Halachmi I (2009) Simulating the hierarchical order and cow queue length in an automatic milking system. Biosyst Eng 102:453-460. https://doi.org/10.1016/j.biosystemseng.2009.01.010

Wang MX, Liu GD, Wu WL, et al. (2006) Prediction of agriculture derived groundwater nitrate distribution in North China Plain with GIS-based BPNN. Environ Geol 50:637-644. https:// doi.org/10.1007/s00254-006-0237-x

Jury WA, Tuli A, Letey J (2003) Effect of travel time on management of a sequential reuse drainage operation. Soil Sci Soc Am J 67:1122-1126

Aerts J-M, Berckmans D (2004) A virtual chicken for climate control design: Static and dynamic simulations of heat losses. Trans Am Soc Agric Eng 47:1765-1772

Lombardo P, Oliver CJ (2002) Optimal classification of polarimetric SAR images using segmentation. IEEE Natl Radar Conf-Proc 8-13. https://doi.org/10.1109/NRC.2002.999684

Heggemann T, Welp G, Amelung W, et al. (2017) Proximal gamma-ray spectrometry for site-independent in situ prediction of soil texture on ten heterogeneous fields in Germany using support vector machines. Soil Tillage Res 168:99-109. https://doi.org/10.1016/j.still .2016 .10 .008 
Table 8 (continued)

Paper ID References

73 Stenzel S, Fassnacht FE, Mack B, Schmidtlein S (2017) Identification of high nature value grassland with remote sensing and minimal field data. Ecol Indic 74:28-38. https://doi. org/10.1016/j.ecolind.2016.11.005

74 Zeng Z, Chen Y, Zhang X (2017) Modelling the interaction of a deep tillage tool with heterogeneous soil. Comput Electron Agric 143:130-138. https://doi.org/10.1016/j.compa g.2017.10.005

Kirchner K, Tölle K-H, Krieter J (2004) The analysis of simulated sow herd datasets using decision tree technique. Comput Electron Agric 42:111-127. https://doi.org/10.1016/S0168 $-1699(03) 00119-4$

Fulton JP, Shearer SA, Stombaugh TS, et al. (2003) Simulation of Fixed- and Variable-Rate Application of Granular Materials. Trans Am Soc Agric Eng 46:1311-1321

Hansen MF, Smith ML, Smith LN, et al. (2018) Towards on-farm pig face recognition using convolutional neural networks. Comput Ind 98:145-152. https://doi.org/10.1016/j.compi nd.2018.02.016

Yu Z, Zhou H, Li C (2017) Fast non-rigid image feature matching for agricultural UAV via probabilistic inference with regularization techniques. Comput Electron Agric 143:79-89. https://doi.org/10.1016/j.compag.2017.10.002

Conţiu Ş, Groza A (2016) Improving remote sensing crop classification by argumentationbased conflict resolution in ensemble learning. Expert Syst Appl 64:269-286. https://doi. org/10.1016/j.eswa.2016.07.037

Chen S, Shao D, Li X, Lei C (2016) Simulation-Optimization Modeling of Conjunctive Operation of Reservoirs and Ponds for Irrigation of Multiple Crops Using an Improved Artificial Bee Colony Algorithm. Water Resour Manag 30:2887-2905. https://doi.org/10.1007/s1126 9-016-1277-y

Osman J, Inglada J, Dejoux J-F (2015) Assessment of a Markov logic model of crop rotations for early crop mapping. Comput Electron Agric 113:234-243. https://doi.org/10.1016/j.compa g.2015.02.015

Moriasi DN, Arnold JG, Vazquez-Amábile GG, Engel BA (2011) Shallow water table depth algorithm in Swat: Recent developments. Trans ASABE 54:1705-1711

Olmstead AL, Rhode P (1988) An overview of California agricultural mechanization, 18701930. Agric Hist 62:86-112

Barth R, IJsselmuiden J, Hemming J, Henten EJV (2018) Data synthesis methods for semantic segmentation in agriculture: A Capsicum annuum dataset. Comput Electron Agric 144:284296. https://doi.org/10.1016/j.compag.2017.12.001

Ye M, Cao Z, Yu Z, Bai X (2015) Crop feature extraction from images with probabilistic superpixel Markov random field. Comput Electron Agric 114:247-260. https://doi.org/10.1016/j. compag.2015.04.010

Kerselaers E, Rogge E, Lauwers L, Van Huylenbroeck G (2015) Decision support for prioritising of land to be preserved for agriculture: Can participatory tool development help? Comput Electron Agric 110:208-220. https://doi.org/10.1016/j.compag.2sss014.10.022

Liao M-S, Chuang C-L, Lin T-S, et al. (2012) Development of an autonomous early warning system for Bactrocera dorsalis (Hendel) outbreaks in remote fruit orchards. Comput Electron Agric 88:1-12. https://doi.org/10.1016/j.compag.2012.06.008

Kamiński Z (2012) Mathematical modelling of the pneumatic relay emergency valve for dualline agricultural trailer braking systems. Proc Inst Mech Eng Part D J Automob Eng 226:603612. https://doi.org/10.1177/0954407011423133 of call feeding for pregnant sows. Comput Electron Agric 79:36-41. https://doi.org/10.1016/j. compag.2011.08.009 gies for forecasting air temperature using geographic information as model predictors. Comput Electron Agric 152:242-260. https://doi.org/10.1016/j.compag.2018.07.008 
Table 8 (continued)

Paper ID References

91 Yang G, Liu L, Guo P, Li M (2017) A flexible decision support system for irrigation scheduling in an irrigation district in China. Agric Water Manag 179:378-389. https://doi.org/10.1016/j. agwat.2016.07.019

Kussul NN, Lavreniuk NS, Shelestov AY, et al. (2016) Land cover changes analysis based on deep machine learning technique. J Autom Inf Sci 48:42-54. https://doi.org/10.1615/JAuto matInfScien.v48.i5.40

Perlman J, Hijmans RJ, Horwath WR (2014) A metamodelling approach to estimate global $\mathrm{N}<$ inf $>2<$ /inf $>\mathrm{O}$ emissions from agricultural soils. Glob Ecol Biogeogr 23:912-924. https ://doi.org/10.1111/geb.12166

Sulistyo SB, Woo WL, Dlay SS (2017) Regularized Neural Networks Fusion and Genetic Algorithm Based On-Field Nitrogen Status Estimation of Wheat Plants. IEEE Trans Ind Informatics 13:103-114. https://doi.org/10.1109/TII.2016.2628439

O'Connell J, Bradter U, Benton TG (2015) Wide-area mapping of small-scale features in agricultural landscapes using airborne remote sensing. ISPRS J Photogramm Remote Sens 109:165-177. https://doi.org/10.1016/j.isprsjprs.2015.09.007

Singh P, Kumar D, Kumar P, et al. (2013) Cryopreservation and Quality Assessment of Buffalo Bull Semen Collected from Farmer's Doorstep. Agric Res 2:148-152. https://doi.org/10.1007/ s40003-013-0056-8

Li YX, Tullberg JN, Freebairn DM, et al. (2008) Effects of tillage and traffic on crop production in dryland farming systems: I. Evaluation of PERFECT soil-crop simulation model. Soil Tillage Res 100:15-24. https://doi.org/10.1016/j.still.2008.04.004

Radcliffe J, Cox J, Bulanon DM (2018) Machine vision for orchard navigation. Comput Ind 98:165-171. https://doi.org/10.1016/j.compind.2018.03.008

99 Kaushik N, Chatterjee N (2018) Automatic relationship extraction from agricultural text for ontology construction. Inf Process Agric 5:60-73. https://doi.org/10.1016/j.inpa.2017.11.003

100 Cavalett O, Chagas MF, Junqueira TL, et al. (2017) Environmental impacts of technology learning curve for cellulosic ethanol in Brazil. Ind Crops Prod 106:31-39. https://doi.org/10.1016/j. indcrop.2016.11.025

Guzhva O, Ardö H, Herlin A, et al. (2016) Feasibility study for the implementation of an automatic system for the detection of social interactions in the waiting area of automatic milking stations by using a video surveillance system. Comput Electron Agric 127:506-509. https:// doi.org/10.1016/j.compag.2016.07.010

102 Muhammad S, Zhan Y, Wang L, et al. (2016) Major crops classification using time series MODIS EVI with adjacent years of ground reference data in the US state of Kansas. Optik (Stuttg) 127:1071-1077. https://doi.org/10.1016/j.ijleo.2015.10.107

Luecke GR (2012) GREENSPACE: Virtual reality interface for combine operator training. Presence Teleoperators Virtual Environ 21:245-253. https://doi.org/10.1162/PRES_a_00110

104 Edan Y, Engel BA, Miles GE (1993) Intelligent control system simulation of an agricultural robot. J Intell \&amp; Robot Syst 8:267-284. https://doi.org/10.1007/BF01257998

Abell KM, Theurer ME, Larson RL, et al. (2017) Predicting bull behavior events in a multiplesire pasture with video analysis, accelerometers, and classification algorithms. Comput Electron Agric 136:221-227. https://doi.org/10.1016/j.compag.2017.01.030

Morales IR, Cebrián DR, Fernandez-Blanco E, Sierra AP (2016) Early warning in egg production curves from commercial hens: A SVM approach. Comput Electron Agric 121:169-179. https://doi.org/10.1016/j.compag.2015.12.009

107 Oksanen T, Linkolehto R, Seilonen I (2016) Adapting an industrial automation protocol to remote monitoring of mobile agricultural machinery: a combine harvester with IoT. IFACPapersOnLine 49:127-131. https://doi.org/10.1016/j.ifacol.2016.10.024

Mishra A, Singh R, Raghuwanshi NS (2005) Development and application of an integrated optimization-simulation model for major irrigation projects. J Irrig Drain Eng 131:504-513. https://doi.org/10.1061/(ASCE)0733-9437(2005)131:6(504) 
Table 8 (continued)

Paper ID References

109 Mekala MS, Viswanathan P (2019) CLAY-MIST: IoT-cloud enabled CMM index for smart agriculture monitoring system. Meas J Int Meas Confed 134:236-244. https://doi.org/10.1016/j. measurement.2018.10.072

110 Rodríguez Alvarez J, Arroqui M, Mangudo P, et al. (2018) Body condition estimation on cows from depth images using Convolutional Neural Networks. Comput Electron Agric 155:12-22. https://doi.org/10.1016/j.compag.2018.09.039

111 Møller AB, Beucher A, Iversen BV, Greve MH (2018) Predicting artificially drained areas by means of a selective model ensemble. Geoderma 320:30-42. https://doi.org/10.1016/j.geode rma.2018.01.018

112 Nasiakou A, Vavalis M, Zimeris D (2016) Smart energy for smart irrigation. Comput Electron Agric 129:74-83. https://doi.org/10.1016/j.compag.2016.09.008

113 Kong C, Lan H, Yang G, Xu K (2016) Geo-environmental suitability assessment for agricultural land in the rural-urban fringe using BPNN and GIS: a case study of Hangzhou. Environ Earth Sci 75:. https://doi.org/10.1007/s12665-016-5956-z

114 Knoll FJ, Czymmek V, Poczihoski S, et al. (2018) Improving efficiency of organic farming by using a deep learning classification approach. Comput Electron Agric 153:347-356. https:// doi.org/10.1016/j.compag.2018.08.032

115 Balducci F, Impedovo D, Pirlo G (2018) Machine learning applications on agricultural datasets for smart farm enhancement. Machines 6:. https://doi.org/10.3390/machines6030038

116 Li W, Ji Z, Wang L, et al. (2017) Automatic individual identification of Holstein dairy cows using tailhead images. Comput Electron Agric 142:622-631. https://doi.org/10.1016/j.compa g.2017.10.029

117 Schmitter P, Steinrücken J, Römer C, et al. (2017) Unsupervised domain adaptation for early detection of drought stress in hyperspectral images. ISPRS J Photogramm Remote Sens 131:65-76. https://doi.org/10.1016/j.isprsjprs.2017.07.003

118 Kortenbruck D, Griepentrog HW, Paraforos DS (2017) Machine operation profiles generated from ISO 11,783 communication data. Comput Electron Agric 140:227-236. https://doi. org/10.1016/j.compag.2017.05.039

119 Sadgrove EJ, Falzon G, Miron D, Lamb D (2017) Fast object detection in pastoral landscapes using a Colour Feature Extreme Learning Machine. Comput Electron Agric 139:204-212. https://doi.org/10.1016/j.compag.2017.05.017

120 Yazdanbakhsh O, Zhou Y, Dick S (2017) An intelligent system for livestock disease surveillance. Inf Sci (Ny) 378:26-47. https://doi.org/10.1016/j.ins.2016.10.026

121 Paraforos DS, Vassiliadis V, Kortenbruck D, et al. (2016) A Farm Management Information System Using Future Internet Technologies. IFAC-PapersOnLine 49:324-329. https://doi. org/10.1016/j.ifacol.2016.10.060

122 Wang K, Wang X, Wu B (2014) Assessment of hygrothermal conditions in a farrowing room with a wet-pad cooling system based on CFD simulation and field measurements. Trans ASABE 57:1493-1500. https://doi.org/10.13031/trans.57.10634

123 Rupnik R, Kukar M, Vračar P, et al. (2019) AgroDSS: A decision support system for agriculture and farming. Comput Electron Agric 161:260-271. https://doi.org/10.1016/j.compa g.2018.04.001

124 Lacoste M, Powles S (2016) Beyond modelling: Considering user-centred and post-development aspects to ensure the success of a decision support system. Comput Electron Agric 121:260268. https://doi.org/10.1016/j.compag.2016.01.003

125 Virk DS, Witcombe JR (2008) Evaluating cultivars in unbalanced on-farm participatory trials. F Crop Res 106:105-115. https://doi.org/10.1016/j.fcr.2007.10.017

126 Paz JO, Batchelor WD, Bullock DG (2002) Technical note: Procedure to use a crop model to identify water-stressed areas in soybean fields using on-farm data. Appl Eng Agric 18:643-646 
Table 8 (continued)

Paper ID References

127 Wang S, Azzari G, Lobell DB (2019) Crop type mapping without field-level labels: Random forest transfer and unsupervised clustering techniques. Remote Sens Environ 222:303-317. https ://doi.org/10.1016/j.rse.2018.12.026

128 Sulistyo SB, Wu D, Woo WL, et al. (2018) Computational Deep Intelligence Vision Sensing for Nutrient Content Estimation in Agricultural Automation. IEEE Trans Autom Sci Eng 15:1243-1257. https://doi.org/10.1109/TASE.2017.2770170

Pérez-Castro A, Sánchez-Molina JA, Castilla M, et al. (2017) cFertigUAL: A fertigation management app for greenhouse vegetable crops. Agric Water Manag 183:186-193. https://doi. org/10.1016/j.agwat.2016.09.013

Blok PM, Barth R, van den Berg W (2016) Machine vision for a selective broccoli harvesting robot. IFAC-PapersOnLine 49:66-71. https://doi.org/10.1016/j.ifacol.2016.10.013

Lin H, Cai K, Chen H, Zeng Z (2015) The construction of a precise agricultural information system based on internet of things. Int J Online Eng 11:10-15. https://doi.org/10.3991/ijoe. v11i6.4847

Liebens J (2001) Spreadsheet macro to determine USDA soil textural subclasses. Commun Soil Sci Plant Anal 32:255-265. https://doi.org/10.1081/CSS-100103005

Clay DE, Chang J, Carlson CG, et al. (2000) Precision farming protocols. Part 2. Comparison of sampling approaches for precision phosphorus management. Commun Soil Sci Plant Anal 31:2969-2985

Oltjen JW, Selk GE, Burditt LG, Plant RE (1990) Integrated expert system for culling management of beef cows. Comput Electron Agric 4:333-341. https://doi.org/10.1016/01681699(90)90038-Q

Ejiri M, Kashioka S, Ueda H (1984) The application of image processing technology to industrial automation. Comput Ind 5:107-113. https://doi.org/10.1016/0166-3615(84)90015-0

Nicoletti J, Ning C, You F (2019) Incorporating agricultural waste-to-energy pathways into biomass product and process network through data-driven nonlinear adaptive robust optimization. Energy 180:556-571. https://doi.org/10.1016/j.energy.2019.05.096

Barth R, IJsselmuiden J, Hemming J, Van Henten EJ (2019) Synthetic bootstrapping of convolutional neural networks for semantic plant part segmentation. Comput Electron Agric 161:291-304. https://doi.org/10.1016/j.compag.2017.11.040

Chang C-L, Lin K-M (2018) Smart agricultural machine with a computer vision-based weeding and variable-rate irrigation scheme. Robotics 7:. https://doi.org/10.3390/robotics7030038

Maddison AL, Camargo-Rodriguez A, Scott IM, et al. (2017) Predicting future biomass yield in Miscanthus using the carbohydrate metabolic profile as a biomarker. GCB Bioenergy 9:1264-1278. https://doi.org/10.1111/gcbb.12418

Xian K (2017) Internet of things online monitoring system based on cloud computing. Int J Online Eng 13:123-131. https://doi.org/10.3991/ijoe.v13i09.7591

Milella A, Reina G, Foglia M (2006) Computer vision technology for agricultural robotics. Sens Rev 26:290-300. https://doi.org/10.1108/02602280610692006

Tappin AD, Harris JRW, Uncles RJ, Boorman D (2002) Potential modification of the fluxes of nitrogen from the Humber Estuary catchment (U.K.) to the North Sea in response to changing agricultural inputs and climate patterns. Hydrobiologia 475-476:65-77. https://doi. org/10.1023/A:1020340620112

Doraiswamy P, Hollinger S, Sinclair TR, et al. (2002) Application of MODIS derived parameters for regional yield assessment. Proc SPIE-Int Soc Opt Eng 4542:1-8. https://doi. org/10.1117/12.454181

Jacucci G, Foy M, Uhrik C (1996) Developing transportable agricultural decision support systems: Part 2. An example. Comput Electron Agric 14:301-315. https://doi.org/10.1016/01681699(96)80778-2 
Table 8 (continued)

Paper ID References

145 Gao J, Meng B, Liang T, et al. (2019) Modeling alpine grassland forage phosphorus based on hyperspectral remote sensing and a multi-factor machine learning algorithm in the east of Tibetan Plateau, China. ISPRS J Photogramm Remote Sens 147:104-117. https://doi. org/10.1016/j.isprsjprs.2018.11.015

146 Sabzi S, Abbaspour-Gilandeh Y (2018) Using video processing to classify potato plant and three types of weed using hybrid of artificial neural network and partincle swarm algorithm. Meas J Int Meas Confed 126:22-36. https://doi.org/10.1016/j.measurement.2018.05.037

147 Kounalakis T, Triantafyllidis GA, Nalpantidis L (2018) Image-based recognition framework for robotic weed control systems. Multimed Tools Appl 77:9567-9594. https://doi.org/10.1007/ s11042-017-5337-y

148 Yan M, Liu P, Zhao R, et al. (2018) Field microclimate monitoring system based on wireless sensor network. J Intell Fuzzy Syst 35:1325-1337. https://doi.org/10.3233/JIFS-169676

149 Yinyan S, Man C, Xiaochan W, et al. (2018) Numerical simulation of spreading performance and distribution pattern of centrifugal variable-rate fertilizer applicator based on DEM software. Comput Electron Agric 144:249-259. https://doi.org/10.1016/j.compag.2017.12.015

150 Terribile F, Bonfante A, D’Antonio A, et al. (2017) A geospatial decision support system for supporting quality viticulture at the landscape scale. Comput Electron Agric 140:88-102. https ://doi.org/10.1016/j.compag.2017.05.028

151 Sanchez-Cohen I, Díaz-Padilla G, Velasquez-Valle M, et al. (2015) A decision support system for rainfed agricultural areas of Mexico. Comput Electron Agric 114:178-188. https://doi. org/10.1016/j.compag.2015.03.009

152 Freeland RS, Buschermohle MJ, Nichols WM (2014) Precision agriculture: RTK base-totractor range limitations using RF communication. Appl Eng Agric 30:97-104. https://doi. org/10.13031/aea.30.10072

153 Hänninen H, Luoranen J, Rikala R, Smolander H (2009) Late termination of freezer storage increases the risk of autumn frost damage to Norway spruce seedlings. Silva Fenn 43:817-830

Feyereisen GW, Sands GR, Strock JS, et al. (2007) Hydrology and nitrogen components of a simple Rye growth model. J Irrig Drain Eng 133:90-99. https://doi.org/10.1061/(ASCE)07339437(2007)133:2(90)

155 Persello C, Tolpekin VA, Bergado JR, de By RA (2019) Delineation of agricultural fields in smallholder farms from satellite images using fully convolutional networks and combinatorial grouping. Remote Sens Environ 231:. https://doi.org/10.1016/j.rse.2019.111253

156 Azzari G, Grassini P, Edreira JIR, et al. (2019) Satellite mapping of tillage practices in the North Central US region from 2005 to 2016. Remote Sens Environ 221:417-429. https://doi. org/10.1016/j.rse.2018.11.010

157 Liu D, Li G, Fu Q, et al. (2018) Application of particle swarm optimization and extreme learning machine forecasting models for regional groundwater depth using nonlinear prediction models as preprocessor. J Hydrol Eng 23:. https://doi.org/10.1061/(ASCE)HE.1943-5584.0001711

Gorczyca MT, Milan HFM, Maia ASC, Gebremedhin KG (2018) Machine learning algorithms to predict core, skin, and hair-coat temperatures of piglets. Comput Electron Agric 151:286294. https://doi.org/10.1016/j.compag.2018.06.028

159 Kaiser A, Erhardt A, Eltner A (2018) Addressing uncertainties in interpreting soil surface changes by multitemporal high-resolution topography data across scales. L Degrad Dev 29:2264-2277. https://doi.org/10.1002/ldr.2967

160 Sadgrove EJ, Falzon G, Miron D, Lamb DW (2018) Real-time object detection in agricultural/ remote environments using the multiple-expert colour feature extreme learning machine (MEC-ELM). Comput Ind 98:183-191. https://doi.org/10.1016/j.compind.2018.03.014

Chelotti JO, Vanrell SR, Galli JR, et al. (2018) A pattern recognition approach for detecting and classifying jaw movements in grazing cattle. Comput Electron Agric 145:83-91. https://doi. org/10.1016/j.compag.2017.12.013 
Table 8 (continued)

Paper ID References

162 Ericson SK, ̊̊strand BS (2018) Analysis of two visual odometry systems for use in an agricultural field environment. Biosyst Eng 166:116-125. https://doi.org/10.1016/j.biosystems eng.2017.11.009

163 Johann AL, de Araújo AG, Delalibera HC, Hirakawa AR (2016) Soil moisture modeling based on stochastic behavior of forces on a no-till chisel opener. Comput Electron Agric 121:420428. https://doi.org/10.1016/j.compag.2015.12.020

164 Qiao Y, Truman M, Sukkarieh S (2019) Cattle segmentation and contour extraction based on Mask R-CNN for precision livestock farming. Comput Electron Agric 165:. https://doi. org/10.1016/j.compag.2019.104958

165 Saldana Ochoa K, Guo Z (2019) A framework for the management of agricultural resources with automated aerial imagery detection. Comput Electron Agric 162:53-69. https://doi. org/10.1016/j.compag.2019.03.028

166 Kale AP, Sonavane SP (2019) IoT based Smart Farming: Feature subset selection for optimized high-dimensional data using improved GA based approach for ELM. Comput Electron Agric 161:225-232. https://doi.org/10.1016/j.compag.2018.04.027

167 Ludeña-Choez J, Choquehuanca-Zevallos JJ, Mayhua-López E (2019) Sensor nodes fault detection for agricultural wireless sensor networks based on NMF. Comput Electron Agric 161:214224. https://doi.org/10.1016/j.compag.2018.06.033

168 Dobrescu R, Merezeanu D, Mocanu S (2019) Context-aware control and monitoring system with IoT and cloud support. Comput Electron Agric 160:91-99. https://doi.org/10.1016/j.compa g.2019.03.005

169 van Zijl G (2019) Digital soil mapping approaches to address real world problems in southern Africa. Geoderma 337:1301-1308. https://doi.org/10.1016/j.geoderma.2018.07.052

170 Espejo-Garcia B, Martinez-Guanter J, Pérez-Ruiz M, et al. (2018) Machine learning for automatic rule classification of agricultural regulations: A case study in Spain. Comput Electron Agric 150:343-352. https://doi.org/10.1016/j.compag.2018.05.007

Yue Y, Cheng X, Zhang D, et al. (2018) Deep recursive super resolution network with Laplacian Pyramid for better agricultural pest surveillance and detection. Comput Electron Agric 150:26-32. https://doi.org/10.1016/j.compag.2018.04.004

Xia J, Yang Y, Cao H, et al. (2018) Hyperspectral identification and classification of oilseed rape waterlogging stress levels using parallel computing. IEEE Access 6:57,663-57,675. https://doi. org/10.1109/ACCESS.2018.2873689

Yang L, Sarath Babu V, Zou J, et al. (2018) The development of an intelligent monitoring system for agricultural inputs basing on DBN-Softmax. J Sensors 2018: https://doi. org/10.1155/2018/6025381

Piero M, Angelo B, Antonello B, et al. (2017) Soil Sealing: Quantifying Impacts on Soil Functions by a Geospatial Decision Support System. L Degrad Dev 28:2513-2526. https://doi. org/10.1002/ldr.2802

175 Bayar G (2017) Development of a Voronoi diagram based tree trunk detection system for mobile robots used in agricultural applications. Ind Rob 44:521-531. https://doi.org/10.1108/IR-112016-0304

176 Pereira MFL, Cruvinel PE (2015) A model for soil computed tomography based on volumetric reconstruction, Wiener filtering and parallel processing. Comput Electron Agric 111:151-163. https://doi.org/10.1016/j.compag.2014.12.006

177 Guedes AL, Moreira M, De M. França MB, et al. (2013) A distributed andwireless data acquisition system to fight against sugarcane orange rust. J Control Autom Electr Syst 24:831-842. https://doi.org/10.1007/s40313-013-0065-7

178 Weiss M, Jacob F, Duveiller G (2020) Remote sensing for agricultural applications: A metareview. Remote Sens Environ 236:. https://doi.org/10.1016/j.rse.2019.111402 
Table 8 (continued)

Paper ID References

179 Saha S, Gayen A, Pourghasemi HR, Tiefenbacher JP (2019) Identification of soil erosionsusceptible areas using fuzzy logic and analytical hierarchy process modeling in an agricultural watershed of Burdwan district, India. Environ Earth Sci 78:. https://doi.org/10.1007/s1266 5-019-8658-5

180 Tatapudi A, Suresh Varma P (2019) Prediction of crops based on environmental factors using iot \&amp; machine learning algorithms. Int J Innov Technol Explor Eng 9:5395-5401. https://doi. org/10.35940/ijitee.A4695.119119

181 Backman J, Linkolehto R, Koistinen M, et al. (2019) Cropinfra research data collection platform for ISO 11,783 compatible and retrofit farm equipment. Comput Electron Agric 166:. https:// doi.org/10.1016/j.compag.2019.105008

182 Zhang Z, Liu H, Meng Z, Chen J (2019) Deep learning-based automatic recognition network of agricultural machinery images. Comput Electron Agric 166:. https://doi.org/10.1016/j.compa g.2019.104978

183 Sakai K, Oishi K, Miwa M, et al. (2019) Behavior classification of goats using 9-axis multi sensors: The effect of imbalanced datasets on classification performance. Comput Electron Agric 166:. https://doi.org/10.1016/j.compag.2019.105027

Bayano-Tejero S, Sola-Guirado RR, Gil-Ribes JA, Blanco-Roldán GL (2019) Machine to machine connections for integral management of the olive production. Comput Electron Agric 166:. https://doi.org/10.1016/j.compag.2019.104980

Kao I-H, Hsu Y-W, Yang Y-Z, et al. (2019) Determination of Lycopersicon maturity using convolutional autoencoders. Sci Hortic (Amsterdam) 256:. https://doi.org/10.1016/j.scien ta.2019.05.065

Kounalakis T, Triantafyllidis GA, Nalpantidis L (2019) Deep learning-based visual recognition of rumex for robotic precision farming. Comput Electron Agric 165:. https://doi.org/10.1016/j. compag.2019.104973

Ranjan RK, Nandi P, Chauhan Y, Jagadeesan J (2019) Determining the yield of the crop using artificial neural network method. Int J Eng Adv Technol 9:2959-2965. https://doi.org/10.35940 /ijeat.A1289.109119

Marino S, Beauseroy P, Smolarz A (2019) Weakly-supervised learning approach for potato defects segmentation. Eng Appl Artif Intell 85:337-346. https://doi.org/10.1016/j.engap pai.2019.06.024

Parente L, Mesquita V, Miziara F, et al. (2019) Assessing the pasturelands and livestock dynamics in Brazil, from 1985 to 2017: A novel approach based on high spatial resolution imagery and Google Earth Engine cloud computing. Remote Sens Environ 232:. https://doi. org/10.1016/j.rse.2019.111301

Ivushkin K, Bartholomeus H, Bregt AK, et al. (2019) Global mapping of soil salinity change. Remote Sens Environ 231:. https://doi.org/10.1016/j.rse.2019.111260

Manoj Athreya A, Hrithik Gowda S, Madhu S, Ravikumar V (2019) Agriculture based recommender system using IoT-A research. Int J Recent Technol Eng 8:1817-1821. https://doi. org/10.35940/ijrte.B1161.0882S819

Renuka, Terdal S (2019) Evaluation of machine learning algorithms for crop yield prediction. Int J Eng Adv Technol 8:4082-4086. https://doi.org/10.35940/ijeat.F8640.088619

Leonard SM, Xin H, Brown-Brandl TM, Ramirez BC (2019) Development and application of an image acquisition system for characterizing sow behaviors in farrowing stalls. Comput Electron Agric 163:. https://doi.org/10.1016/j.compag.2019.104866

Bishop JC, Falzon G, Trotter M, et al. (2019) Livestock vocalisation classification in farm soundscapes. Comput Electron Agric 162:531-542. https://doi.org/10.1016/j.compag.2019.04.020

Ennouri K, Kallel A, Albano R (2019) Remote sensing: An advanced technique for crop condition assessment. Math Probl Eng 2019:. https://doi.org/10.1155/2019/9404565 S.2019.2910986 
Table 8 (continued)

Paper ID References

197 Christiansen MP, Teimouri N, Laursen MS, et al. (2019) Preprocessed sentinel-1 data via a web service focused on agricultural field monitoring. IEEE Access 7:65,139-65,149. https://doi. org/10.1109/ACCESS.2019.2917063

198 Xin W, Yu W, Yuanyuan Z, et al. (2018) Intelligent Gateway for Heterogeneous Networks Environment in Remote Monitoring of Greenhouse Facility Information Collection. IFACPapersOnLine 51:217-222. https://doi.org/10.1016/j.ifacol.2018.08.146

199 Miranda J, Ponce P, Molina A, Wright P (2019) Sensing, smart and sustainable technologies for Agri-Food 4.0. Comput Ind 108:21-36. https://doi.org/10.1016/j.compind.2019.02.002

200 Mondino P, Gonzalez-Andujar JL (2019) Evaluation of a decision support system for crop protection in apple orchards. Comput Ind. https://doi.org/10.1016/j.compind.2019.02.005

201 Coulibaly S, Kamsu-Foguem B, Kamissoko D, Traore D (2019) Deep neural networks with transfer learning in millet crop images. Comput Ind. https://doi.org/10.1016/j.compi nd.2019.02.003

202 Vasconez JP, Kantor GA, Auat Cheein FA (2019) Human-robot interaction in agriculture: A survey and current challenges. Biosyst Eng 179:35-48. https://doi.org/10.1016/j.biosystems eng.2018.12.005

203 Tsolakis N, Bechtsis D, Bochtis D (2019) Agros: A robot operating system based emulation tool for agricultural robotics. Agronomy 9:. https://doi.org/10.3390/agronomy9070403

204 Bechtsis D, Moisiadis V, Tsolakis N, et al. (2019) Unmanned Ground Vehicles in Precision Farming Services: An Integrated Emulation Modelling Approach

205 Sengupta T, Narayanamurthy G, Moser R, Hota PK (2019) Sharing app for farm mechanization: Gold Farm's digitized access based solution for financially constrained farmers. Comput Ind. https://doi.org/10.1016/j.compind.2019.04.017

Acknowledgements The authors would like to thank the editors and the reviewers providing developmental and constructive feedback and comments on the earlier versions of the manuscript.

Funding Not applicable.

Availability of data and material Not applicable.

\section{Compliance with ethical standards}

Conflict of interest The authors have no conflicts of interests or competing interests.

Open Access This article is licensed under a Creative Commons Attribution 4.0 International License, which permits use, sharing, adaptation, distribution and reproduction in any medium or format, as long as you give appropriate credit to the original author(s) and the source, provide a link to the Creative Commons licence, and indicate if changes were made. The images or other third party material in this article are included in the article's Creative Commons licence, unless indicated otherwise in a credit line to the material. If material is not included in the article's Creative Commons licence and your intended use is not permitted by statutory regulation or exceeds the permitted use, you will need to obtain permission directly from the copyright holder. To view a copy of this licence, visit http://creativecommons.org/licenses/by/4.0/. 


\section{References}

Adams, R., Jeanrenaud, S., Bessant, J., Denyer, D., \& Overy, P. (2015). Sustainability-oriented innovation: A systematic review. International Journal of Management Reviews, 18(2), 180-205. https://doi. org/10.1111/ijmr.12068.

Barmpounakis, S., Kaloxylos, A., Groumas, A., Katsikas, L., Sarris, V., Dimtsa, K., et al. (2015). Management and control applications in agriculture domain via a future internet business-to-business platform. Information Processing in Agriculture, 2(1), 51-63. https://doi.org/10.1016/j.inpa.2015.04.002.

Boshkoska, B. M., Liu, S., Zhao, G., Fernandez, A., Gamboa, S., del Pino, M., et al. (2019). A decision support system for evaluation of the knowledge sharing crossing boundaries in agri-food value chains. Computers in Industry, 110, 64-80. https://doi.org/10.1016/j.compind.2019.04.012.

Brewster, C., Roussaki, I., Kalatzis, N., Doolin, K., \& Ellis, K. (2017). IoT in agriculture: designing a Europe-wide large-scale pilot. IEEE Communications Magazine, 55(9), 26-33. https://doi.org/10.1109/ MCOM.2017.1600528.

Carayannis, E. G., Rozakis, S., \& Grigoroudis, E. (2018). Agri-science to agri-business: The technology transfer dimension. Journal of Technology Transfer, 43(4), 837-843. https://doi.org/10.1007/s1096 $1-016-9527-y$.

CEMA - European Agricultural Machinery. (2017). FARMING 4.0: THE FUTURE OF AGRICULTURE? http://www.cema-agri.org/page/farming-40-future-agriculture. Retrieved 10 September, 2019

Colicchia, C., \& Strozzi, F. (2012). Supply chain risk management: A new methodology for a systematic literature review. Supply Chain Management, 17(4), 403-418. https://doi.org/10.1108/135985412112465 58.

Corallo, A., Latino, M. E., \& Menegoli, M. (2018). From industry 4.0 to agriculture 4.0: A framework to manage product data in agri-food supply chain for voluntary traceability. International Journal of Nutrition and Food Engineering, 12(5), 146-150. https://doi.org/10.1109/ieem.2014.7058728.

Darnhofer, I., Bellon, S., Dedieu, B., \& Milestad, R. (2009). Adaptiveness to enhance the sustainability of farming systems. Sustainable Agriculture, 30(3), 545-555. https://doi. org/10.1007/978-94-007-0394-0_4.

Delbufalo, E. (2012). Outcomes of inter-organizational trust in supply chain relationships: A systematic literature review and a meta-analysis of the empirical evidence. Supply Chain Management, 17(4), 377-402. https://doi.org/10.1108/13598541211246549.

Denyer, D., \& Tranfield, D. (2009). Producing a systematic review. In D. A. Buchanan \& A. Bryman (Eds.), The Sage handbook of organizational research methods (pp. 671-689). Thousand Oaks: Sage Publications Ltd.

Fountas, S., Sorensen, C. G., Tsiropoulos, Z., Cavalaris, C., Liakos, V., \& Gemtos, T. (2015). Farm machinery management information system. Computers and Electronics in Agriculture, 115, 40-50. https:// doi.org/10.1016/j.compag.2014.11.011.

George, G., Haas, M. R., \& Pentland, A. (2014). Big data and management. Academy of Management Journal, 57(2), 321-326. https://doi.org/10.5465/amj.2014.4002.

Günther, W. A., Mehrizi, M. H. R., Huysman, M., \& Feldberg, F. (2017). Debating big data: A literature review on realizing value from big data. The Journal of Strategic Information Systems, 26(3), 191-209.

Kaloxylos, A., Eigenmann, R., Teye, F., Politopoulou, Z., Wolfert, S., Shrank, C., et al. (2012). Farm management systems and the future internet era. Computers and Electronics in Agriculture, 89, 130-144. https://doi.org/10.1016/j.compag.2012.09.002.

Karim, F., Karim, F., \& Frihida, A. (2017). Monitoring system using web of things in precision agriculture. Procedia Computer Science, 110, 402-409. https://doi.org/10.1016/j.procs.2017.06.083.

Kitchenham, B., Pearl Brereton, O., Budgen, D., Turner, M., Bailey, J., \& Linkman, S. (2009). Systematic literature reviews in software engineering - a systematic literature review. Information and Software Technology, 51(1), 7-15. https://doi.org/10.1016/j.infsof.2008.09.009.

Knippenberg, D. V., Dahlander, L., Haas, M. R., \& George, G. (2015). Information, attention, and decision making. Academy of Management Journal, 58(3), 649-657.

Kouadio, L., Deo, R. C., Byrareddy, V., Adamowski, J. F., Mushtaq, S., \& Phuong Nguyen, V. (2018). Artificial intelligence approach for the prediction of Robusta coffee yield using soil fertility properties. Computers and Electronics in Agriculture, 155, 324-338. https://doi.org/10.1016/j.compa g.2018.10.014.

Lampridi, M. G., Kateris, D., Vasileiadis, G., Marinoudi, V., Pearson, S., Sørensen, C. G., et al. (2019). A case-based economic assessment of robotics employment in precision arable farming. Agronomy. https ://doi.org/10.3390/agronomy9040175. 
Lehmann, R. J., Reiche, R., \& Schiefer, G. (2012). Future internet and the agri-food sector: State-of-theart in literature and research. Computers and Electronics in Agriculture, 89, 158-174. https://doi. org/10.1016/j.compag.2012.09.005.

Lezoche, M., Panetto, H., Kacprzyk, J., Hernandez, J. E., \& Alemany Díaz, M. M. E. (2020). Agri-food 4.0: A survey of the supply chains and technologies for the future agriculture. Computers in Industry, 89, 158-174. https://doi.org/10.1016/j.compind.2020.103187.

Mikalef, P., \& Pateli, A. (2017). Information technology-enabled dynamic capabilities and their indirect effect on competitive performance: Findings from PLS-SEM and fsQCA. Journal of Business Research, 70, 1-16. https://doi.org/10.1016/j.jbusres.2016.09.004.

Mikalef, P., Pappas, I. O., Krogstie, J., \& Pavlou, P. A. (2020). Big data and business analytics: A research agenda for realizing business value. Information \& Management, 57(1), 103237.

Nukala, R., Panduru, K., Shields, A., Riordan, D., Doody, P., \& Walsh, J. (2016). Internet of things: A review from "Farm to Fork." In 27th Irish Signals and Systems Conference (ISSC), Londonderry, 2016, pp. 1-6. https://doi.org/10.1109/ISSC.2016.7528456

Pappas, I. O., Mikalef, P., Giannakos, M. N., Krogstie, J., \& Lekakos, G. (2018). Big data and business analytics ecosystems: Paving the way towards digital transformation and sustainable societies. Information Systems and e-Business Management, 16(3), 479-491.

Pittaway, L., Robertson, M., Munir, K., Denyer, D., \& Neely, A. (2004). Networking and innovation: A systematic review of the evidence. International Journal of Management Reviews, 5(3-4), 137-168. https ://doi.org/10.1111/j.1460-8545.2004.00101.x.

Rigby, D., Woodhouse, P., Young, T., \& Burton, M. (2001). Constructing a farm level indicator of sustainable agricultural practice. Ecological Economics, 39(3), 463-478. https://doi.org/10.1016/S0921 $-8009(01) 00245-2$.

Sharif, A. M., \& Irani, Z. (2017). Policy making for global food security in a volatile, uncertain, complex and ambiguous (VUCA) world. Transforming Government: People, Process and Policy, 11(4), 523534. https://doi.org/10.1108/TG-08-2017-0050.

Sivarajah, U., Kamal, M. M., Irani, Z., \& Weerakkody, V. (2017). Critical analysis of big data challenges and analytical methods. Journal of Business Research, 70, 263-286. https://doi.org/10.1016/j.jbusr es.2016.08.001.

Spanaki, K., Gürgüç, Z., Adams, R., \& Mulligan, C. (2018). Data supply chain (DSC): Research synthesis and future directions. International Journal of Production Research, 56(13), 4447-4466. https://doi. org/10.1080/00207543.2017.1399222.

Tranfield, D., Denyer, D., \& Smart, P. (2003). Towards a methodology for developing evidence-informed management knowledge by means of systematic review. British Journal of Management, 14(3), 207222. https://doi.org/10.1111/1467-8551.00375.

Tripicchio, P., Satler, M., Dabisias, G., Ruffaldi, E., \& Avizzano, C. A. (2015). Towards smart farming and sustainable agriculture with drones. In Proceedings-2015 International Conference on Intelligent Environments, IE 2015. https://doi.org/10.1109/IE.2015.29

Tsolakis, N., Bechtsis, D., \& Srai, J. S. (2019). Intelligent autonomous vehicles in digital supply chains: From conceptualisation, to simulation modelling, to real-world operations. Business Process Management Journal, 25(3), 414-437. https://doi.org/10.1108/BPMJ-11-2017-0330.

Tzounis, A., Katsoulas, N., Bartzanas, T., \& Kittas, C. (2017). Internet of things in agriculture, recent advances and future challenges. Biosystems Engineering, 164, 31-48. https://doi.org/10.1016/j.biosy stemseng.2017.09.007.

United Nations. (2017a). The Sustainable Development Goals Report. United Nations Publications. https:// doi.org/10.18356/3405d09f-en. Retrieved 10 September, 2019

United Nations. (2017c). Global indicator framework for the Sustainable Development Goals and targets of the 2030 Agenda for Sustainable Development. https://unstats.un.org/sdgs/indicators/Global\%20Ind icator\%20Framework\%20after\%202020\%20review_Eng.pdf. Retrieved 10 September, 2019

Wezel, A., Bellon, S., Doré, T., Francis, C., Vallod, D., \& David, C. (2009). Agroecology as a science, a movement and a practice. Agronomy for Sustainable Development, 29(4), 503-515. https://doi. org/10.1007/978-94-007-0394-0_3.

Wezel, A., Casagrande, M., Celette, F., Vian, J., Ferrer, A., \& Peigné, J. (2014). Agroecological practices for sustainable agriculture A review. Agronomy for Sustainable Development, 34(1), 1-20. https://doi. org/10.1007/s13593-013-0180-7.

Wolfert, S., Ge, L., Verdouw, C., \& Bogaardt, M. J. (2017). Big data in smart farming-a review. Agricultural Systems, 153, 69-80. https://doi.org/10.1016/j.agsy.2017.01.023.

Yahya N. (2018) Agricultural 4.0: Its implementation toward future sustainability. In: Green urea. Green energy and technology. Springer, Singapore. https://doi.org/10.1007/978-981-10-7578-0_5 
Zambon, I., Cecchini, M., Egidi, G., Saporito, M. G., \& Colantoni, A. (2019). Revolution 4.0: Industry vs. agriculture in a future development for SMEs. Processes. https://doi.org/10.3390/pr7010036.

Publisher's Note Springer Nature remains neutral with regard to jurisdictional claims in published maps and institutional affiliations. 